\title{
Ancient History of the Arbins, Bearers of Haplogroup R1b, from Central Asia to Europe, 16,000 to 1500 Years before Present
}

\author{
Anatole A. Klyosov \\ The Academy of DNA Genealogy, Newton, USA \\ Email: aklyosov@comcast.net
}

Received March $14^{\text {th }}, 2012$; revised April $13^{\text {th }}, 2012$; accepted April $23^{\text {rd }}, 2012$

\begin{abstract}
This article aims at reconstructing the history of R $1 \mathrm{~b}$ ancient migrations between 16,000 and 1500 years before present (ybp). Four thousand four hundred eight (4408) haplotypes of haplogroup R1b (with subclades) were considered in terms of base (ancestral) haplotypes of R1b populations and the calculated time to their common ancestors. The regions considered are from South Siberia/Central Asia in the east (where R1b haplogroup arose $\sim 16,000 \mathrm{ybp}$ ) via the North Kazakhstan, South Ural to the Russian Plain and further west to Europe (the northern route entering Europe around $4500 \mathrm{ybp}$ ); from the Russian Plain south to the Caucasus (6000 ybp), Asia Minor (6000 ybp) and the Middle East (6000 - $5500 \mathrm{ybp}$ ) to the Balkans in Europe (the southern route, entering Europe around $4500 \mathrm{ybp}$ ); along North Africa and the Mediterranean Sea (5500 - 5000 ybp) via Egypt to the Atlantic, north to Iberia (the North African route with arrival to the Pyrenees $4800 \mathrm{ybp}$ ). The Arbins (bearers of R1b haplogroup) along their migration route to the Middle East and South Mesopotamia apparently have established the Sumer culture (and the state), moving westward to Europe (5000 - 4500 ybp) carrying mainly the R-M269 subclade and its downstream L23 subclade. This last subclade was nearly absent along the North African route, and/or did not survive the migration to Iberia or evidenced later. At the arrival to Iberia (4800 ybp) the M269 subclade split off M51 and soon thereafter the L11 downstream subclades. These populations became known as the Bell Beakers and moved north, along with the newly arisen subclades of P312 and L21 (which split off within a few centuries after P312). Those subclades and their downstream clades have effectively, without major interruptions, populated Europe (the smooth haplotype trees demonstrate the near non-stop proliferation of R1b haplotypes in Europe). They are evidenced from the Atlantic eastward to the Balkans, Carpathian Mountains, present day Poland to the western border of the Russian Plain and up to the Baltic Sea. The Isles had a different history of R1b migrations. The bearers of L11, P312 and L21 moved to the Isles by land and sea concurrently with those Arbins who were populating Europe between 4000 and 2500 ybp and formed the respective "local" subclades of P314, M222, L226, which largely populated the Isles. As a result, a significant part of the Isles is populated almost exclusively by the Arbins, whose frequency reaches $85 \%$ - 95\% among the current population. In general, the frequency of Arbins in Western and Central Europe, reaches - albeit not uniformly-some $60 \%$ of the population. This study essentially presents an example of application of DNA genealogy in studying the history of mankind.
\end{abstract}

Keywords: Y Chromosome; Mutations; Haplotypes; Haplogroups; TMRCA; STR; SNP; Arbins; Aryans; $\mathrm{R} 1 \mathrm{~b}$

\section{Introduction}

The origin and history of haplogroup R1b, bearers I refer to as the Arbins (see explanation below), currently populate nearly $60 \%$ of Western and Central Europe. Additionally Arbins populate significant parts of the Caucasus, Anatolia and Asia Minor, Middle East, and many locations in Central Asia, including South Siberia, Altay, Tuva, North-Western China, Middle Asia, some Ural and Middle Volga regions with ethnic groups and populations such as the Bashkirs, Tatars, Chuvash, and other.

History of R1b was significantly distorted from the beginning of "genetic genealogy" at the end of 1990-s, when it was claimed, quite groundlessly, that R1b arose in Europe some 30,000 years before present (ybp). Groundlessly because, indeed, the claims were based on no data. Such data never existed. Nevertheless, statements and claims such as "Around 30,000 years ago, a descendant of the clan making its way into Europe gave rise to marker M343, the defining marker of haplogroup $R 1 b$. These travelers are direct descendants of the people who dominated the human expansion into Europe, the Cro-Magnon" (Spencer Wells, "Deep Ancestry", 2006). This and similar claims, such as R1b (and its M269 subclades) were "well established throughout Paleolithic Europe", "contemporaneous with Aurignacian culture", "the earliest expansion into Europe, during the Upper Paleolithic $\sim 30,000$ years ago" by Wells, Semino, Underhill, Cavalli-Sforza, Cinnioglu, Kivisild, Wiik and many others (e.g., Semino et al., 2000; Wells et al., 2001; Cinnioglu et al., 2004; Wiik, 2008) were essentially based on "thoughts" that if people lived in Europe some 30,000 years ago, they necessarily were of the R1b haplogroup, and not of I, G, J, E, F or any other haplogroups. Were any haplotypes analyzed? Their mutations counted? Any chronological evaluations? There was nothing of the above.

"Paleolithic origin" of R1b in Europe, or their "Paleolithic migrations" to Europe around 10,000 - 8000 ybp are still claimed 
in recent academic papers, such as (Myres et al., 2010; Balaresque et al., 2010; Morelli et al., 2010). These assumptions and resulting calculations are based, typically, on "population mutation rates" (Zhivotovsky et al., 2004; Hammer et al., 2009; Underhill et al., 2009), which commonly exaggerate the chronological estimates of migrations and events by $200 \%-400 \%$ since they are based on crude, artificial and unrealistically naïve and generalized reasoning (for critique, see Klyosov, 2009a, 2009b, 2009c; Rozhanskii \& Klyosov, 2011). The "academic papers", placing origin of R1b in Asia Minor or nearby, have not considered regions east of Asia Minor as well as R1b haplotypes of those eastern regions. In short, the whole story of R1b migrations and their history is in disarray, and the "population geneticists" continue to advance misleading conclusions due to their methodology.

This study's methodology/analysis includes considerations of Y chromosome extended 67 and 111 marker haplotypes, when available. The methodology was described in detail in the preceding papers in this journal (Rozhanskii \& Klyosov, 2011; Klyosov \& Rozhanskii, 2012a) and elsewhere (e.g., Klyosov, 2009a, 2009c, 2009d), and in Materials and Methods section of this article.

As described (Klyosov \& Rozhanskii, 2012b), Europeoids (Caucasoids) appeared $\sim 58,000$ ybp. They gradually branched to downstream haplogroups and their subclades, and migrated to the north, west, south and east. Haplogroup NOP, which was among them, arose $\sim 48,000 \mathrm{ybp}$, and moved eastward, presumably towards South Siberia and/or adjacent regions. Haplogroup P split off $\sim 38,000$ ybp, presumably in South Siberia, and gave rise to haplogroup $\mathrm{R}$ and then $\mathrm{R} 1 \sim 30,000-26,000$ ybp (see the diagram in Klyosov and Rozhanskii, 2012b). Haplogroup R1b arose $\sim 16,000 \mathrm{ybp}$, as it will be shown further in this paper.

The timing may be reconstructed from a series of R1b haplotypes, made available from the databases (see Appendix). The most distant R1b haplotypes (those exhibiting the greatest mutational differences) from European R1b haplotypes, were found in Siberia and Middle Asia (a part of Central Asia) populations. Central Asian R1b haplotype bearers have the most ancient common ancestors with European R1b bearers, and those ancient common ancestors lived $\sim 16,000$ ybp in Central Asia. We do not know as yet whether in South Siberia or Middle Asia; however, the evidence will demonstrate that it was somewhere in that vast region.

In this endeavor both terms, "haplogroup" and "subclade", are employed as near equivalents because all haplogroups are essentially subclades of other upstream haplogroups, and usage of one or the other of these terms is suggested by the context. This is shown in the following diagram (ISOGG-2012, a fragment, http://www.isogg.org/tree/ISOGG_HapgrpR.html) which is related to the most ancient subclades of $\mathrm{R} 1 \mathrm{~b}$ haplogroup:

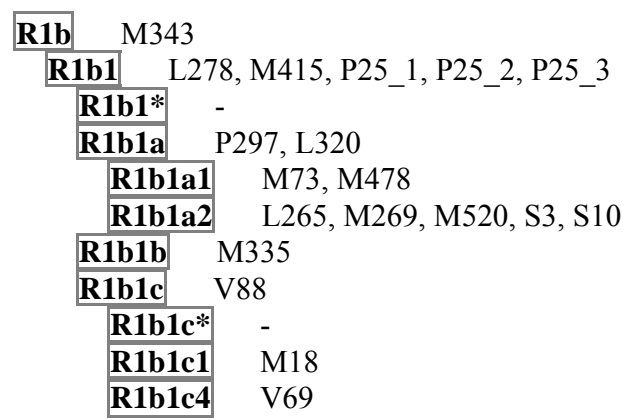

Due to lack of a common name for bearers of R1b haplogroup (with subclades) and their languages in ancient times, which were carried for millennia and eventually brought to Europe as non-Indo European languages, I refer to them as the Arbins (from R1b), both the people and their original languages, on the analogy with the Aryans, who essentially belonged to haplogroup R1a (Klyosov \& Rozhanskii, 2012a).

\section{A Bird's-Eye View at R1b Haplotypes, and the Most Ancient R1b Populations}

Figure 1 presenting an overview of an R1b haplotype tree includes 338 haplotypes in a short 8 marker format. The purpose of the presentation is to show the complex pattern of the R1b haplogroup and identify the most ancient branch on the tree.

The haplotype tree as shown next is arranged by a computer program which combines branches based on the similarity of their alleles in the respective markers (or loci) in Y chromosome, and dynamics of their alleles (Klyosov, 2009c and references therein). Haplotypes identical to each other and prevail-

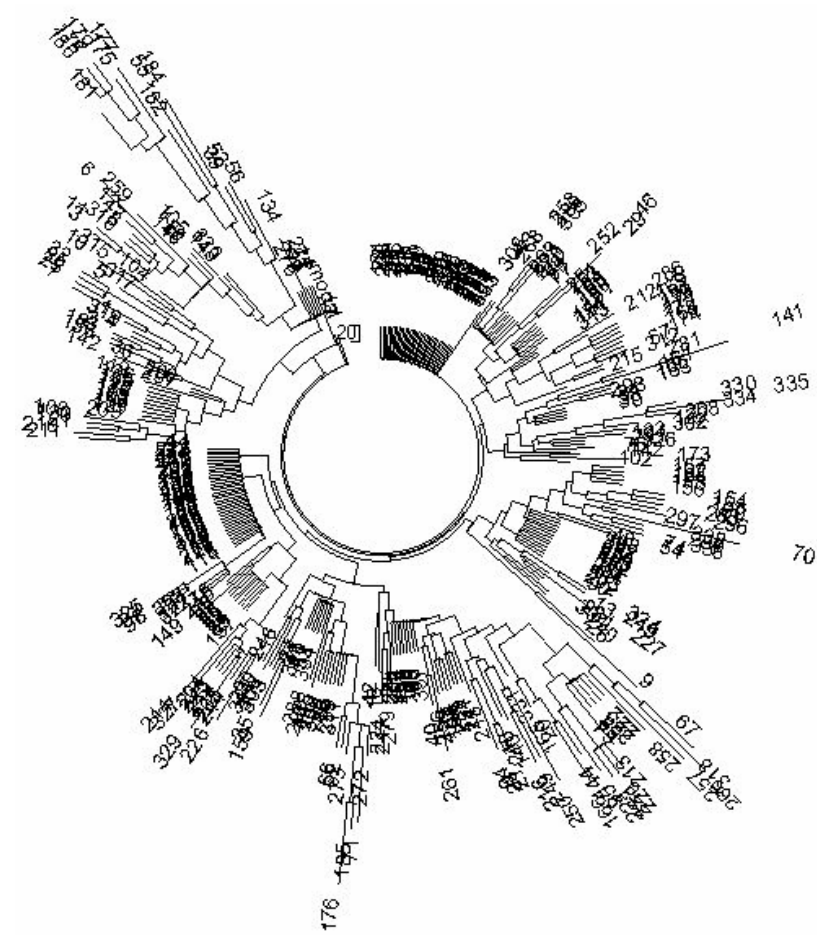

Figure 1.

The 8-marker 338 haplotype tree for R1b1 haplotypes, composed from data listed in (Zhong et al., 2010). The tree includes haplotypes of subclade $\mathrm{R} 1 b^{*}$ ( 8 haplotypes), R1b1* (2 haplotypes), R1b1c ( 2 haplotypes), R1b (140 haplotypes), R1b1a1 (12 haplotypes), R1b2b (21 haplotypes), R1b1a2 (153 haplotypes). Regarding ethnicity and/or location, the haplotypes belong to 40 Western Europeans, 17 Iberians, 84 Turks, 48 Albanians, Macedonians and Romanians, 40 Italians, 30 Cretans, 13 Greeks and Macedonians, 9 Romanians from a different region, 13 Pakistanis, 4 Indians, 2 Japanese, 2 Mongolians (one of them, No. 176, belongs to R1b1b1-M73 subclade and stands out in the lower part of the tree), 2 Tibetans, 1 Kyrgyz from Xinjiang, 7 Han Chinese, 16 Uighur (12 from the Xinjiang Province, six of them belong to R1b subclade, three R1b1b1 and three R1b1b2); four Chinese (three R1b2b and one R1b1b2), 2 Chinese of the Hui tribe, and 6 Chinese of other ethnicities (Hazak R1b1b1, Tu R1b2b, and four Naxi R1b2b). 
ing in the dataset are sitting at the top of the tree; in relatively recent datasets they typically represent the "base", or "ancestral" haplotype, from which all other haplotype are derived through mutations. Branches which are located close to the "trunk" of the tree contain not many mutations from the base haplotype, hence, they are relatively "young". The most ancient branches are those which shoot away from the trunk since they contain the most mutations in their haplotypes.

In Figure 1 that rather recent and prevailing R1b branch has its base haplotype 13241411 X X X 12 X 1313 29. Thirtyfive of those identical haplotypes sit on the top of the tree. Here $\mathrm{X}$ stand for missing alleles in the haplotype presented in the standard twelve marker FTDNA format (for definitions see Materials and Methods). This base haplotype belongs to the most populous European base haplotypes of the subclade R-M269, which in turn includes subclade R-P312 and its many downstream subclades. For example, the base 67 marker haplotype of P312 subclade is as follows (Klyosov, 2011b):

132414111114121212131329 - 17910111125 $15192915151717-1111192315151817363812$

12 - 1191516810108101012232316101212158

1222201312111311111212

(P312)

The alleles identical to those of the apparent "base" haplotype in the tree in Figure 1 are marked in bold. Indeed, the subclade R1b1a2-M269 takes the largest part of the tree in Figure 1, since "R1b" as indicated in the legend is largely R-M269 as well.

The analysis of the tree shows that many of the Asian R1b haplotypes, particularly all the Indian, most of Pakistani, a quarter of Uighurs, one Japanese, one Tibetan, and two Chinese Hans are not the "indigenous" haplotypes but those which are closely associated with European haplotypes and share with them the same branches (Klyosov, 2010a). In other words, they are "returns" to the regions with Europeans, or having the European R1b origin. They are indistinguishable from the European R1b haplotypes.

Some of haplotypes, however, form separate branches. The most remarkable branch is most remote from the trunk, hence, the most ancient, is located in the upper left part of the tree. It contains 12 haplotypes which all belong to R1b1a1-M73 and R1b-M343 subclades, and provided by Uighurs and the close tribes of the Naxi, Han and Tu (Zhong et al., 2010). All the 12 haplotypes are derived from the base haplotype 132415 11/10 X X X 12 X 14/13 1230 , and contain collectively 65 mutations from it. Using the "linear" formula, we obtain $65 / 12 / .013=417$ $\rightarrow 619$ conditional generations (the arrow here is a correction for back mutations), or 15,475 \pm 2500 years from their common ancestor (the calculation is explained in the Materials and Methods section). This date is in a fair agreement with $16,000 \pm$ 1400 years from a common ancestor of R1b haplotypes (Klyosov, 2008a, 2009d) and will be additionally confirmed later in this paper. It also indicates that the R1b haplogroup arose in Central Asia, and, apparently, in the Altay region in South Siberia, where their upstream haplogroups $\mathrm{NOP} \rightarrow \mathrm{NO}+\mathrm{P} ; \mathrm{P} \rightarrow$ $\mathrm{R}+\mathrm{Q} ; \mathrm{R} \rightarrow \mathrm{R} 1+\mathrm{R} 2 ; \mathrm{R} 1 \rightarrow \mathrm{R} 1 \mathrm{a}+\mathrm{R} 1 \mathrm{~b}$ all migrated and lived there during the time period between 52 and 20-15 thousand years before present (Klyosov \& Rozhanskii, 2012b).

\section{Siberian, Bashkir, and Central Asian R1b-M73 Haplotypes}

Although the M73 subclade is positioned a few steps from the top of the above diagram, it contains the most distant available haplotypes from the Europeans, both geographically and by their mutations. Figures 2 and $\mathbf{3}$ show two M73 haplotype trees composed from two different datasets; one was obtained directly from the researchers and published earlier (Klyosov, 2008a), the second was collected from the R1b1b1 Haplogroup Project (see Figure 3 and references). Both of them have principally the same shape, with two primary branches in Figure 2 and three in Figure 3.

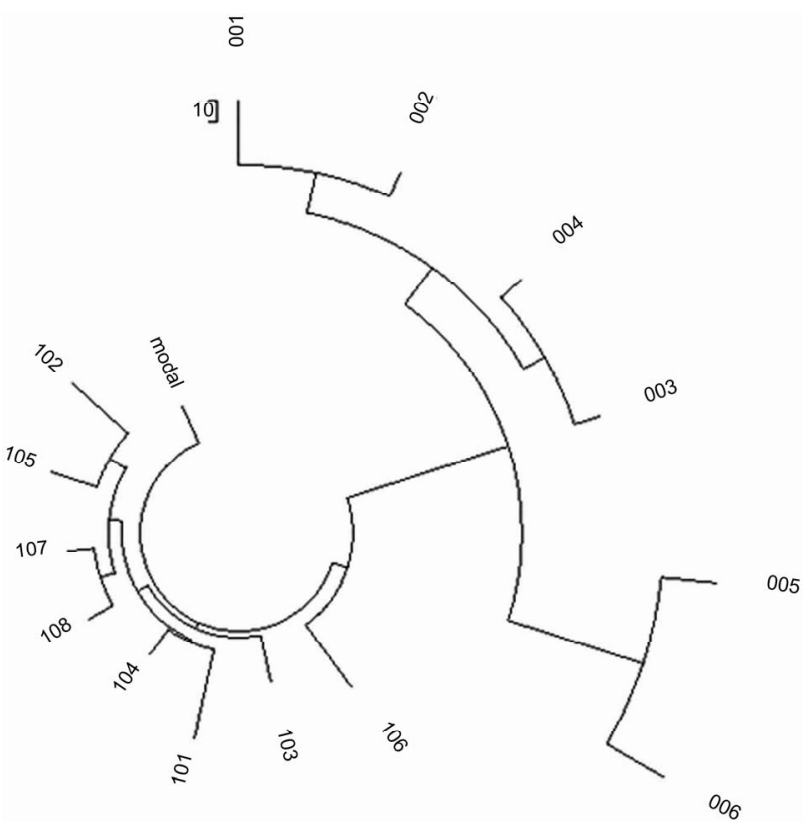

Figure 2.

The 25-marker 14 haplotype tree for R1b1-M73 haplotypes in Central Asia (Uzbeks, Tajiks, Tuva, Uighurs, Kazakhs) (Klyosov, 2008a).

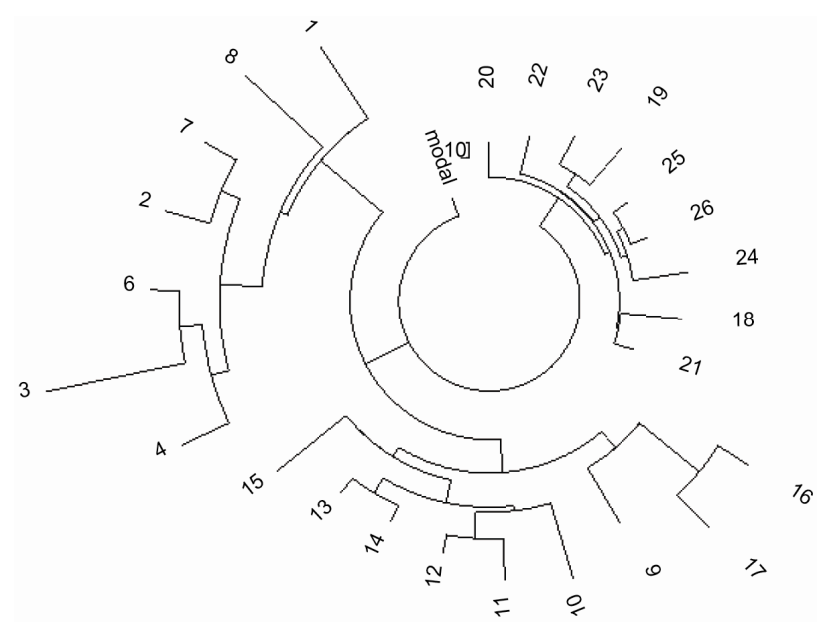

Figure 3.

The 25-marker 25 haplotype tree for R1b1a1-M73 haplotypes: the righthand side branch-five Russians, three Kazakhs, one Chinese; the lower branch-four Uzbeks, two Tajiks, one Turk, one from Luxembourg; the left-hand branch - two English, two Italians, one French and one Spanish. The data are taken from the FTDNA Project, in which many haplotypes are available in the 67 marker format: http://www.familytreedna.com/public/R1b1b1/default.aspx?section=yre sults. 
The tight 8-haplotype branch close to the "trunk" of the tree in Figure 2 and the 9-haplotype right-hand branch in Figure 3 both have the same base haplotype as follows:

$131914111313121213141330-179911112315$ $193312151516-101019251516161730361210$ $-118161681010811101223231610121216812$ $24211312111311111211 \quad$ (M73, branch)

The remarkable feature of this base haplotype (and every haplotype in the both branches) is the second allele, DYS390 = 19. In the 25 marker format, the branches contain 15 and 17 mutations respectively, which gives the same $1075 \pm 280$ years to the common ancestor in both instances.

It should be mentioned here that a similar series of ten R-M73 haplotypes (with DYS $390=19$ ) were obtained from the Bashkir population (Myres et al., 2010) near the border between Europe and Asia, on both sides of the Ural Mountains. Their base haplotype was 13191410 X X X 1213141329 10 (the last marker is DYS461), and all hundred alleles in the ten haplotypes contained only three mutations; this gives $3 / 10 / .018=17$ generations, or $425 \pm 250$ years to their common ancestor. However, as it will be shown below, a common ancestor of these and other R-M73 haplotypes lived more that 10 thousand years ago. What we see in these haplotypes are essentially "tips of the iceberg;" they are tremendously distant from each other and must be very remote from their common ancestor in time. It seems that the "base" of the proverbial iceberg vanished without leaving their ancient haplotypes behind. In other words, we see here a series of present-day haplotypes which either arrived from elsewhere a few centuries earlier, or went through a severe bottleneck(s) of the population.

The Bashkir's (similar or slightly mutated) R-M73 haplotypes were identified among Tatars and Mari populations, in the adjacent regions (ibid.). In the same study, the R-M73 were found also among Kabardino-Balkars, Mengrels, Turks, with all speaking Turkic or Uralic languages, which belong to the Altay language family. Another name for Mari people is Cheremis, meaning "people from the East" in a neighboring Komi language. Their base haplotype 13221411 X X X 1213 141332 - 10 differs by 7 mutations (!) in ten markers from the Bashkir base L23 haplotype, which places their common ancestor by $9700 \mathrm{ybp}$ (Klyosov, 2011a), and if haplotypes with DYS390 = 19 are included, their common ancestor moves deeper in time, to at least 16,000 years before present.

Revisiting the tree in Figure 3, the lower branch in the tree has the following base haplotype (when extended to 67 markers)

$$
\begin{aligned}
& 132214111317121212131330-159911112315 \\
& 203012151517-111019241514171735391210 \\
& \text { - } 118161681010810101223231510121218912 \\
& \begin{array}{llllllllll}
25 & 20 & 13 & 12 & 11 & 13 & 11 & 11 & 12 & 12
\end{array}
\end{aligned}
$$

and its common ancestor lived $3525 \pm 600 \mathrm{ybp}$. It corresponds to the right branch in Figure 2.

The left-hand side branch in Figure $\mathbf{3}$ has the following base haplotype:

$122514111314121212141329-16910111122$ $15203212151617-1110192515171718343614$ $10-1181616811108111012222317101212158$ $1322201412111411111212 \quad$ (M73, branch) and its common ancestor lived $3050 \pm 600 \mathrm{ybp}$.

All three branches are rather "young", however, they all are very distant from each other. Their pair-wise mutational differences are 38, 38 and 42, which translates into the separation time between their common ancestors as 11,500 - 13,200 years of the mutational evolution in their haplotypes (we call it the "lateral time" between two base haplotypes). All three M73 base haplotypes differ from each other collectively by 62 mutations, which place their common ancestor at $\sim 7750 \mathrm{ybp}$. However, their mutational difference is even more pronounced when compared with the base haplotype of R1b1a2-P312 subclade, ancestral to many European subclades of R1b1a2 haplotypes. For the above M73 base haplotypes it amounts to 48, 35 and 42 mutations, or up to 16,000 years of the mutational difference between the two base haplotypes. This places their common ancestor at $10,600 \mathrm{ybp}$.

Another series of 26 of 12 marker M73 haplotypes was listed in (Malyarchuk et al., 2011), and were collected among the Siberian populations: Shors, Teleuts, Kalmyks, Khakass, Tuva, and Altayans. Those haplotypes split into two branches. The first one fits exactly to the first 67 marker base haplotypes with their available 12 markers; the second deviates from the base haplotype of the respective right-hand branch in Figure 2 in two alleles (marked):

131914111313 X X $13141330-1510$

132214111316 X X $13131330-1510$

The first 12 marker base haplotype is a mixed Siberian-UralCaucasian population (if to consider their current bearers-Bashkirs, Kalmyks, Tuva, Tatar, Kabardin, Russian, and Altayan). All 11 haplotypes of this branch have collectively 20 mutations, which gives $20 / 11 / .024=76 \rightarrow 83$ conditional generations, or, $2075 \pm 510$ years to a common ancestor. The logarithmic method gives $[\ln (11 / 2)] / .024=71 \rightarrow 77$ generations, or 1925 years, which is nearly the same ( 2 haplotypes are identical in their base haplotypes among 11 haplotypes in the dataset. .024 is the mutation rate constant for the 12 marker haplotypes). The same but in 67 markers, Middle Asian M73 haplotypes showed $1075 \pm 280$ years to the common ancestor. Thus, the SiberiaUral-Caucasian dataset is somewhat "older" compared to the Middle Asian dataset.

The second 12 marker base haplotype was largely from Siberian populations (Shors, Teleuts, Khakasses), plus a singular Mari, Turk and Tatar each. All 15 haplotypes of this branch had 22 mutations, which gives 22/15/.024 $=61 \rightarrow 65$ conditional generations; or $1625 \pm 380$ years to a common ancestor. The logarithmic method gives $[\ln (15 / 5)] / .024=46 \rightarrow 48$ generations, or $1200 \pm 580$ years, which is the same within the margin of error. The 67 marker base haplotype, however showed 3525 \pm 600 years to the common ancestor. Hence, now the MiddleAsian M73 branch is "older" compared to the Siberian. Overall, the Siberian and Middle Asian haplotypes were in about the same estimate of "age".

The two 12 marker haplotypes differ by 8 mutations, which sets their two common ancestors apart by $8 / .024=333 \rightarrow 492$ generations, or 12,300 years. It gives $(12,300+2075+1625) / 2=$ 7985 ybp to their common ancestor. One can see that the data obtained with the 67 and 12 marker haplotypes of the M73 subclade from Siberia and Middle Asia are fairly reproducible, and point to a common ancestor of Central Asian M73 haplotypes nearly $8000 \mathrm{ybp}$. It should be kept in mind that these data 
are related to currently living descendants of those common ancestors. We also need to be mindful that the 67 marker M73 Central Asian haplotype examples a distance up to 48 mutations from the European R1b1a2 haplotypes, which is up to 16,000 years of the mutational difference between the two base haplotypes. This places their (R-M73 in Central Asia and R-M269 in Europe) common ancestor at 10,600 years before present.

\section{R1b1-L278/R1b1 ${ }^{*}$ Subclade Haplotypes}

The most ancient subclades of R1b are considered by the Project R1b1 (xP297); xP297 does not include subclades M73 and M269, discussed in the preceding section of this article. All 68 haplotypes of the Project which are available in the 67 marker format are shown in the tree in Figure 4. The tree includes haplotypes of subclade R1b1 ${ }^{*}$, a para-group of R1b1-L278 (see the R1b diagram exampled previously), V88, its downstream subclade V69, and a series of haplotypes R1b1a2-M269 which are in the Project apparently by mistake (however, useful in the tree as a reference branch).

A detailed analysis of the tree was performed in (Klyosov, 2011a). Haplotypes of the R1b1 ${ }^{*}$ para-group are represented in the Project by either Ashkenazi Jews (from Hungary, Russia, Belarus) with their very recent common ancestors a few centuries ago, or by very assorted geography - from Italy, Puerto-Rico, Germany, Armenia, Turkey. Formally, a triple branch on the right of Figure 4 (haplotypes 1 - 10) has a common ancestor who lived about $5800 \mathrm{ybp}$. It does not carry any certain historical meaning judging from their composition except, the time span corresponds to that of R-L23 subclade in the Caucasus and Anatolia (Klyosov, 2010d); R-L23 was certainly not alone there. Those assorted haplotypes could have been brought by their ancestors from Central Asia along with R-M269 followed by

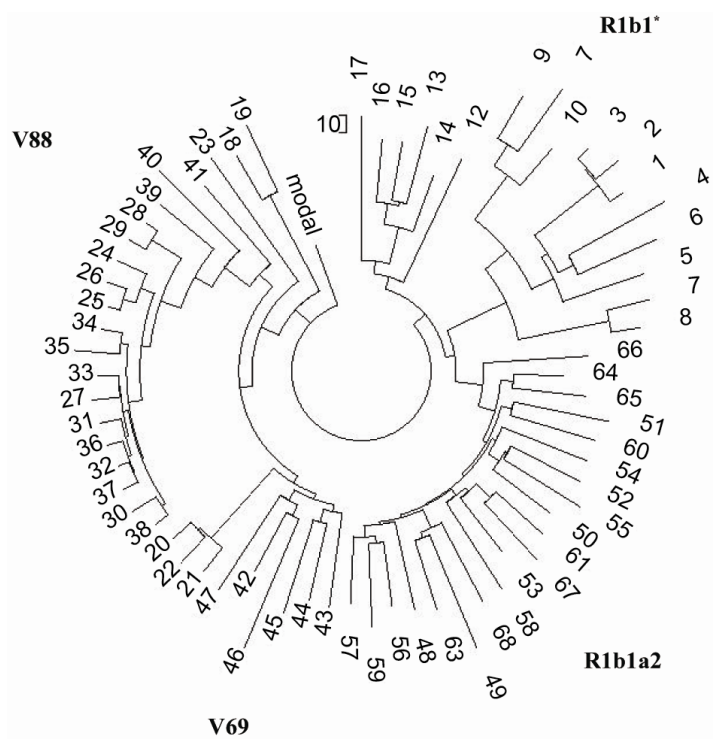

Figure 4.

67 marker haplotype tree of 68 haplotypes of subclades R $1 b 1^{*}$ (1 - 17), R1b1c-V88 (18 - 41), R1b1c4-V88-V69 (42 - 47), R1bla2 $(48-68)$. The tree was composed from data of the FTDNA Project

http://www.familytreedna.com/public/R1b1Asterisk/default.asp $\mathrm{x}$ ? section $=$ yresults.
L23 haplotypes, and eventually dispersed across Europe.

The next small branch of six haplotypes $(12-17)$ includes those from Central Asia (Uzbek), Armenia, Middle East (Iraq and Bahrain), India, and Germany (the last being relatively close to the Uzbek haplotype, within 4900 years of the mutational evolution). The Indian haplotype has DYS390 $=18$, which brings it closer to the Central Asian haplotypes with DYS390 $=19$, considered above. Others have DYS390 $=24$ or 25. Their mutational deviations (without inclusion of the very distant haplotype) from base $\mathrm{R} 1 \mathrm{~b} 1$ * haplotype

$$
\begin{aligned}
& 132415101213 / 14121311 / 12131329 \text { - } 14991111 \\
& 26 \text { 14/15 } 183013 / 1414 \text { 14/15 } 16 \text { - } 11111823151618 \\
& 1636361311-1181516810108111012192116 \\
& 101212 \text { 14/1581224 20/211411 } 111312111212
\end{aligned}
$$

(R1b1*, branch)

in the first 25, 37, and 67 markers suggests 238, 217, and 235 generations from their common ancestor (without a correction for back mutations), that is $230 \pm 11$ generations, a fairly reproducible value. The most reliable value, for the 67 marker format, gives $\sim 8400$ years to their common ancestor. However, the Indian haplotype differs from the above base haplotype by 62.5 mutations (!), with its DYS390 = 18 contributing only 6 mutations into the difference. This places a timespan to the $\mathrm{R} 1 \mathrm{b1}{ }^{*}$ common ancestor (of the available haplotypes) to 16,600 years before present. It certainly points to Central Asia, since the European-Middle Eastern R1b1 ${ }^{*}$ haplotypes are only $\sim 8400$ years "old"

\section{R1b1c-V88 Subclade in Europe and Africa}

Haplotypes V88 occupy the left-hand side of the tree in Figure 4. Again, a number of their sub-branches are quite "young". For example, a part of the branch belongs to Ashkenazi Jews (Russia, Ukraine, Hungary, Germany, France) with a common ancestor of only $350 \mathrm{ybp}$. Haplotypes of England and Scotland have a common ancestor who lived $650 \mathrm{ybp}$. However, a common ancestor of the two sub-branches (Jews and the Isles) lived $6875 \mathrm{ybp}$, at the very bottom of the V88 subclade. Another series of V88 haplotypes identifies their route from Saudi Arabia (6225 ybp) via Spain to the Jewish community (1525 ybp, in the middle of the $1^{\text {st }}$ millennium $\mathrm{CE}$ ). The base haplotype of the V88 branch in Figure 4 is as follows:

132416101314121212141329 - 16/179 101112 $2614192912121515-111221231515181933$ $35 / 361211-1281516810108911122223151112$

$\begin{array}{llllllllllllll}12 & 15 & 8 & 12 / 13 & 23 & 20 & 13 & 12 & 11 & 13 & 11 & 12 & 12 & 12\end{array} \quad$ (V88)

and its bearer lived $6575 \pm 700 \mathrm{ybp}$.

A rather extended series of 72 of 11 marker V88 haplotypes from Africa was provided in (Cruciani et al., 2010). They split into two rather distinct branches and an assorted series of haplotypes (Klyosov, 2010b). One branch of 37 haplotypes has the following base haplotype (in the format - 413a,b 460, 461, GATA A10, YCAIIa,b after the first standard 12 markers, some of them are missing): 13 X 1511 X X X X 12 X X X - 232111 10132123 All of them contain 111 mutations, which gives $111 / 37 / .02=150 \rightarrow 176$ conditional generations, or $4400 \pm 610$ years to their common ancestor. This African V88 base haplotype does not fit with either of the Eurasian V88 base haplotypes, however, it fits rather well to the R1b1c4-V69 base haplotype (see the next section), whose common ancestor lived 
$4300 \pm 600 \mathrm{ybp}$. The paper (Cruciani et al, 2010) suggested one more subclade named R1bla4, with 29 haplotypes. Their base haplotype is identical with that shown above; all 29 haplotypes contain 76 mutations, and gives 76/29/.02 $=131 \rightarrow 150$ generations, or $3750 \pm 570 \mathrm{ybp}$, which is within the margin of error with the above date.

Another branch of V88 African haplotypes is recent with a common ancestor of $750 \pm 290 \mathrm{ybp}$. All 72 African haplotypes have the same base haplotype as shown above with 201 mutations from it, which gives $201 / 72 / .020=140 \rightarrow 163$ generations, or $4075 \pm 500 \mathrm{ybp}$, within the margin of error of that for the main V88 branch; however, the first is more accurate since it was calculated for the distinct branch.

This date, $4300 \pm 600 \mathrm{ybp}$, fits well with that for the migration route of R1b bearers from the Middle East westward along the Mediterranean Sea coast to the Atlantic, which took place between 5500 and $4800 \mathrm{ybp}$ (see below). It seems that the R1b-V88-V69 tribe may have split altering migration direction south, to Cameroon and Chad, where R1b-V88 bearers live today.

\section{R1b1c4-V69 Subclade}

This subclade is represented by six haplotypes at the bottom of the tree in Figure 4, with the base haplotype

132315111315121213131329 - 16/179 10 11 12

$27141929121214 \quad 15-111221231516171933$

$36 / 371212-128151681010810111221241511$

$121214812 / 1322201312111311121213 \quad$ (V69)

All of them collectively have 106 mutations from the base haplotype, which gives $106 / 6 / .12=147 \rightarrow 172$ generations, or $4300 \pm 600$ years from a common ancestor. This is in agreement with the "age" of the upstream V88 subclade, of $\sim 6575$ ybp. The V69 base haplotype differs by 16 mutations from the base V88 haplotype (see above; some mutations are fractional), which sets apart their common ancestors by $16 / .12=133 \rightarrow$ 154 generations, or 3850 years, and places their common ancestor at $(3850+6575+4300) / 2=7400 \pm 800 \mathrm{ybp}$. This is within the margin of error with $6575 \pm 700 \mathrm{ybp}$ for the V88 upstream subclade.

The analysis demonstrates that R-V88 is a rather "young" subclade in comparison with the entire R1b, and R-V69 is "younger". It may have arisen on the R1b general migration route to the Middle East, for example, north-east or east of the Caspian Sea, in the Western Iran.

\section{R1b1a2-M269 Subclade}

The last branch on the tree in Figure 4 in the lower righthand side has the base haplotype

$132414111114121212131329-17910111125$

$15192915151717-1111192315151817373812$

12 - 1191516810108101012232316101212158

$1222201312111311111212 \quad$ (M269, a mix)

It is exactly the base haplotype of subclades R-P312 and R-L21. They are typical and widespread European haplotypes. All 20 haplotypes of the branch contain 365 mutations, which gives $365 / 20 / .12=152 \rightarrow 179$ generations, or $4475 \pm 505$ years to their common ancestor. This, again, is a typical "age" for a mix of haplotypes of subclades R-P312 and R-L21 and their downstream subclades.
The M269 subclade along with its downstream subclades were analyzed in many publications (Klyosov, 2008a, 2009d, 2010c, 2010d, 2010e, 2011a, 2011b). In short, this subclade arose around $7000 \mathrm{ybp}$ in Central Asia or in the eastern area of the Russian Plain - its immediate downstream subclade R-L23 (arose $\sim 6000 \mathrm{ybp}$ ) is widespread among the Bashkirs in the South Urals, North Kazakhstan and adjacent regions, and can be seen in Russia. It migrated south to the Caucasus and beyond, to Anatolia and the Middle East. Nearly all principal European and Middle Eastern subclades of the R1b haplogroup (currently more than 80 subclades) are derived from the R1b1a2-M269 subclade.

It should be mentioned here, that two brother subclades, R1a and R1b, have been migrating from Central Asia westward by two quite different routes. While R1a were moving along the southern route from the Altay region across the Himalayas, Hindustan, the Iranian plateau, Anatolia and the balance of Asia Minor to the Balkans (Klyosov \& Rozhanskii, 2012), R1b were moving along the northern route, from the same region across South Urals, Middle Asia, North Kazakhstan, Middle Volga, the Caucasus, and then split between the southward and westward directions. This migration pattern also explains why R1a, but not R1b bearers were found in the Eastern Himalayas (Kang et al., 2011; see also Klyosov \& Rozhanskii, 2012).

37 and 67 marker haplotype trees of the R1bla2 ${ }^{*}$-M269 subclade are shown in Figures 5 and 6, respectively. The trees contain two distinct branches, one rather complex and obviously "older", with the base haplotype

$122514111114111212131329-17910111125$ 15192915151617 - 1011192315151917353812

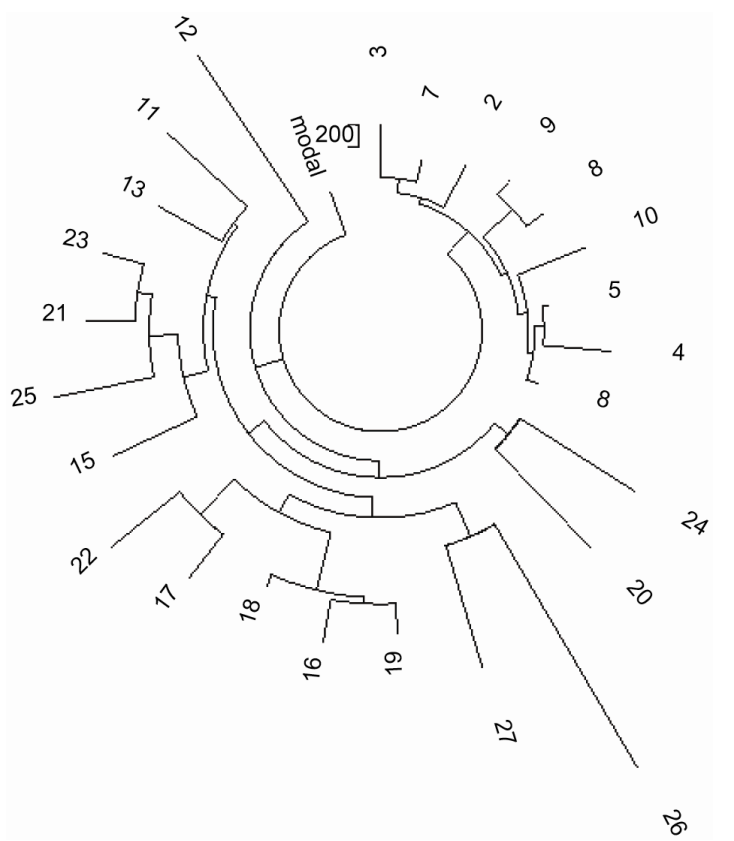

Figure 5.

The 37 marker 25-haplotype tree for R1b1a2 ${ }^{*}$-M269 haplotypes. The older $(\sim 6225 \mathrm{ybp})$ branch on the left and the bottom present haplotypes from Turkey, Armenia, Italy, France, England. The younger $(1000 \mathrm{ybp})$ branch in the upper right side represents Ukraine, Belarus, Poland, and Kazakhstan.

http://www.familytreedna.com/public/ht35new/default.aspx 


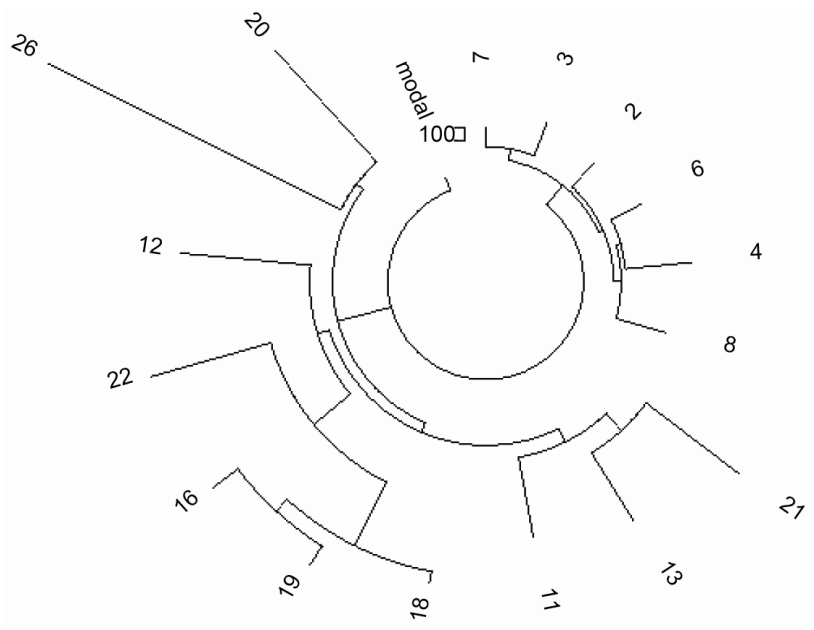

Figure 6.

The 67 marker haplotype tree for R1b1a2 ${ }^{*}$-M269 haplotypes, the same dataset as shown in Figure 5, however, with fewer haplotypes available.

\section{2 - 1191516810108111012232316101212158 1322201312111311111212 \\ (M269)}

and another, a tight, flat, "younger”, and largely Jewish branch, with the base haplotype.

$122414101114111212131429-17910111125$

15193015151616 - 1110192317161717383913

12 - 1191516810108111012212316101212148

$1222201312111310111212 \quad$ (M269, Jewish)

Mutation deviations between the two are shown in bold. The younger branch has 26 mutations in all six 67 marker haplotypes, which gives $26 / 6 / .12=36 \rightarrow 37$ conditional generations, or $925 \pm 200$ years to a common ancestor. The 37 marker branch contains 31 mutation in nine haplotypes, which gives $31 / 9 / .09=38 \rightarrow 40$ generations, or $1000 \pm 200$ years-essentially the same. This Jewish population exemplified with 14 of 37 marker haplotypes was analyzed earlier (Klyosov, 2008b) and determined that their common ancestor lived $1100 \pm 250$ ybp; the base haplotype is exactly as that of the "young" branch listed above.

The older branch has a common ancestor who lived $6200 \pm$ $900 \mathrm{ybp}$. The two base haplotypes differ by 22 mutations which separate them by $22 / .12=183 \rightarrow 224$ generations, or 5600 years, and a common ancestor of both branches lived $6400 \pm$ 900 ybp.

This description gives us a general picture of migration of the Arbins from Central Asia ( 16,000 ybp) westward during the next 10 - 9 thousand years, to about $7000-6000 \mathrm{ybp}$.

\section{Haplogroup R1b (mainly R1b1a2-L23) among Bashkirs, and in the Caucasus, Anatolia, Middle East}

R-L23 apparently arose on the eastern side of the Russian Plain, where Europe meets Asia, $6200 \mathrm{ybp}$ and migrated to the Caucasus and further South, to Anatolia and the Middle East. Another branch of L23 went westward, to Europe, approximately $4500 \mathrm{ybp}$.

The most eastern population with the prevailing R-L23 sub- clade is the Bashkirs, a Turkic-language people who live largely on both sides of the Ural Mountains and in North Kazakhstan. Frequency of R1b haplogroup reaches $84 \%$ in the Perm Bashkirs, $81 \%$ among Baimak Bashkirs, and lower figures in other Bashkir tribes (Lobov, 2009). 29 of 10 marker haplotypes of subclade R-L23 of the Bashkirs were published (Myres et al., 2010), and their base haplotype is $12241410 \mathrm{X}$ X X 1212131330 - 10. This is a typical albeit slightly mutated L23 haplotype with its characteristic first allele DYS393 = 12. 26 haplotypes of those 29 were identical, as shown above, and the whole Bashkir L23 branch has a common ancestor who lived only $575 \pm 175 \mathrm{ybp}$. However, this base haplotype differs from the European R-L23 base haplotype 12241410 X X X 1212131429 - 11 by three mutations, which sets these two base haplotypes apart by $3 / .018=167 \rightarrow 200$ conditional generations - 5000 years, and places their common ancestor at 5500 ybp. Other Bashkir haplotypes belonged to R-M269 (one haplotype), R-M73 (10 haplotypes), and R-U152 (8 haplotypes). The last series of haplotypes were all identical to each other, and thus are derived from a very recent common ancestor, who certainly had a European origin [U152 arose in Europe $4125 \pm$ 450 ybp (Klyosov, 2011b)].

We therefore see today's reflection of ancient migrations of the Arbins westward from Central Asia, apparently from the South Siberian region, across the South Urals and further to the Russian Plain and then the Caucasus.

Almost all R1b1a2 haplotypes in the Caucasus region belong to the subclade L23 (with its characteristic DYS393 = 12). In a recent paper (Balanovsky et al., 2012) 90 Caucasian haplotypes of R1b haplogroup were listed, and with exception of five R1b haplotypes and a relatively "young" Abkhazian branch (Figure 7) 79 of 81 haplotypes (97.5\%) in the dataset were of the L23 subclade (Note: the cited paper did not consider haplotype trees nor has analyzed the haplotypes in the manner presented here).

The same pattern is observed with Armenian R1b haplotypes, and with most of Anatolian R1b haplotypes (Klyosov, 2010c, 2011c). The 67 marker base R-L23 haplotype, obtained from an extended haplotype dataset from the world over (tree Figure 8) is as follows:

122414111114121212131329 - 16910111125 15192915151617 - 1111192316151717363712 12 - 1191516810108101112232316101212158 1222201312111311111212

The L23 base short Caucasian haplotype in Figure 7 fits exactly to the above haplotype (the matching alleles are marked in bold). A common ancestor of the L23 subclade lived $\sim 6200 \mathrm{ybp}$ (Klyosov, 2010d, 2011a). 81 Caucasian L23 haplotypes containing 425 mutations from their base haplotype, give 425/ $81 / .035=150 \rightarrow 176$ conditional generations, or $4400 \pm 490$ years to their common ancestor. The "younger" date (compared with the "age" of L23 of about $6200 \mathrm{ybp}$ ) can be explained by a detailed consideration of an extended series of 107 of R-L23 haplotypes listed in the FTDNA Project (see the legend in Figure 8). The tree in Figure 8 splits into two parts. On the left are 38 haplotypes, with the base

122414111215121212131329 - 16910111125 $15193015151618-1111192316161817363712$ $12-1191516810108111112232315101212168$ $1222201312111311111212 \quad$ (L23, branch) 


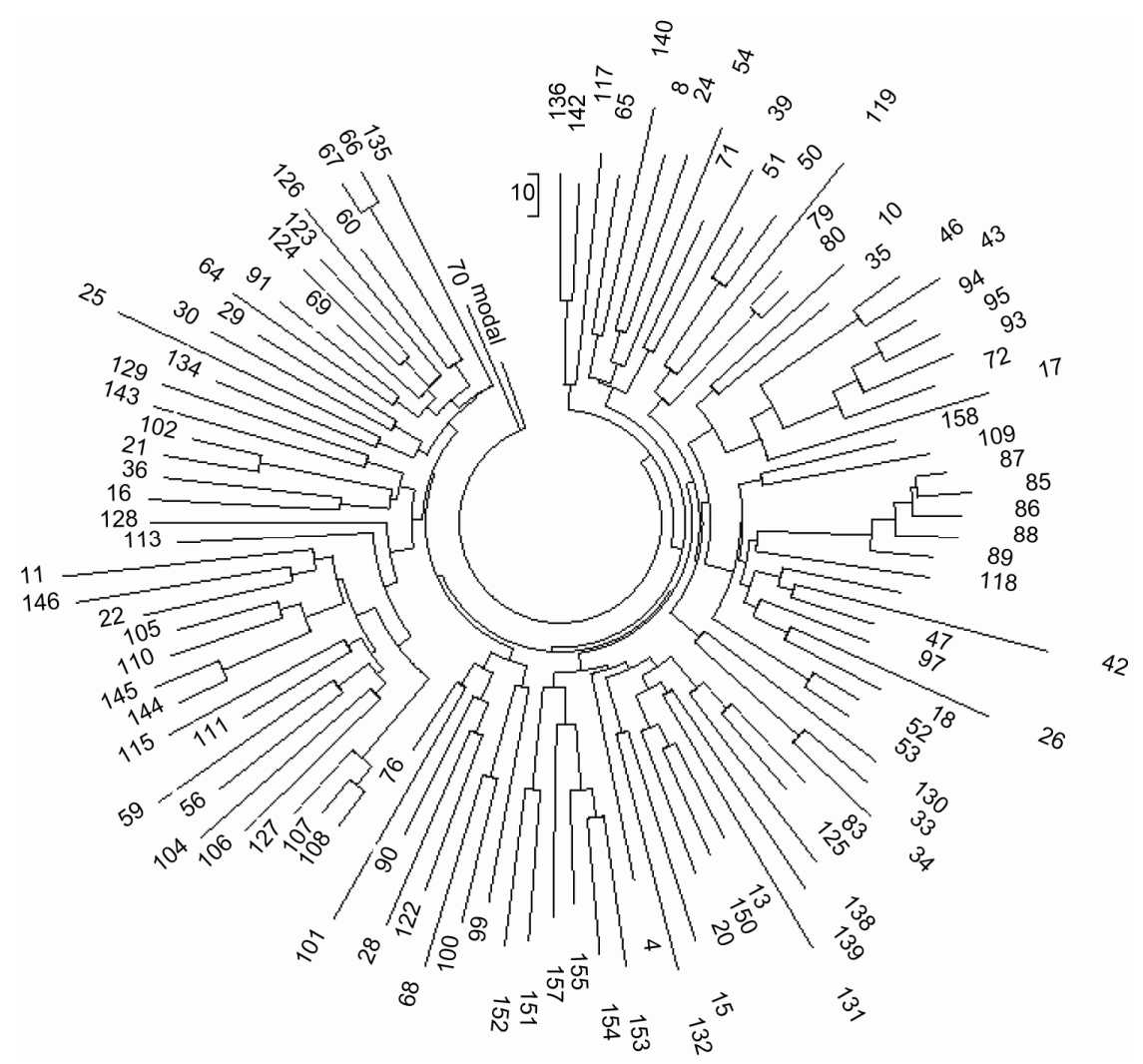

Figure 8.

The 67-marker tree composed with 107 haplotypes of the subclade R-L23. 40\% of the haplotypes belong to Armenians and Turks, followed by Iraqis and Italians ( $5 \%$ each). The haplotypes were collected in the FTDNA Project http://www.familytreedna.com/public/ht35new/default.aspx

It gives $784 / 115 / .034=201 \rightarrow 250$ conditional generations, or $6250 \pm 660$ years from the common ancestor. This again is a typical timespan to a common ancestor of R-L23 subclade, and is in an agreement with the "age" of its upstream R-M269 subclade of $\sim 7000 \mathrm{ybp}$.

The same base haplotype, as shown in the preceding paragraph, was found in a dataset of 238 Armenian six-marker R1b haplotypes published earlier (Weale et al., 2001) and analyzed in (Klyosov, 2008a). It included haplotypes from six regions of Armenia, Karabakh, Iran, and other areas of the Armenian diaspora. It can be presented as 12241411 X X X 12 X X 13 X. An average "age" of the common ancestor of R1b haplotypes in all the six regions was $5750 \pm 1500$ years, which is in line with other estimates for the R-L23 subclade.

Considering other populations, containing a rather high share of R-L23 haplotypes, which in turn could be a tracer of ancient migration of the Arbins, one can mention Russia with their 37\% of available R1b haplotypes having DYS393 = 12 (Roewer et al., 2008; Klyosov, 2010c and references therein) and the base haplotype 122414111114 X X 121313 29/30 - 161519 (the last three alleles are of DYS $458,437,448$ ), the same as R-L23, shown above, and with a common ancestor of the Russian R1b of $6775 \pm 830$ ybp (Klyosov, 2009d); Anatolia and Lebanon with their 12241411 X X X 12131329 and 1224 1410 X X X 12131329 (mutated DYS391 $11 \rightarrow 10$ is marked) and with the respective common ancestors of $6000 \pm 820 \mathrm{ybp}$ (Anatolia) and $5200 \pm 670 \mathrm{ybp}$ (Lebanon) [Klyosov, 2010c; haplotypes were listed in Cinnioglu et al., 2004, and Zalloua et

\section{al., 2008].}

Among Jewish R1b haplotypes (most were not typed for subclades when tested several years ago as the typing was not available), one branch remarkably resembled R-L23 haplotypes, and its 37 marker base haplotypes was as follows (Klyosov, 2008b):

$$
\begin{aligned}
& 122414101114121212131429-17910111125 \\
& 15192915151617 \text { - } 1111192316161817373812 \\
& 12 \\
& \text { (L23, Jewish) }
\end{aligned}
$$

In this particular instance the dataset contained 42 of 37 marker haplotypes, which collectively had 620 mutations; this gives $620 / 42 / .09=164 \rightarrow 196$ generations, or $4900 \pm 530$ years from a common ancestor. The base haplotype differs by $9 \mathrm{mu}-$ tations from the "young" Jewish base haplotype above in its first 37 markers, which makes the 4900 ybp haplotype likely ancestral. The oldest identified Jewish Rlb base haplotype, is of $5400 \pm 500 \mathrm{ybp}$ (Klyosov, 2008b). It has certainly appeared in the Middle East, during the Sumerian era.

\section{Sumers, the likely Bearers of R1b1a2 Haplotypes, and Their Descendant Assyrians}

Assyrians are one of the oldest surviving groups descended, as it is believed, from the historic Sumers. Among Assyrians, $\mathrm{R} 1 \mathrm{~b}$ is the major haplogroup, reaching $40 \%$ of the studied population; haplogroup $\mathrm{J}$ takes second place with $11 \%$ and others are in singular percentages (Lashgary et al., 2011). Such 


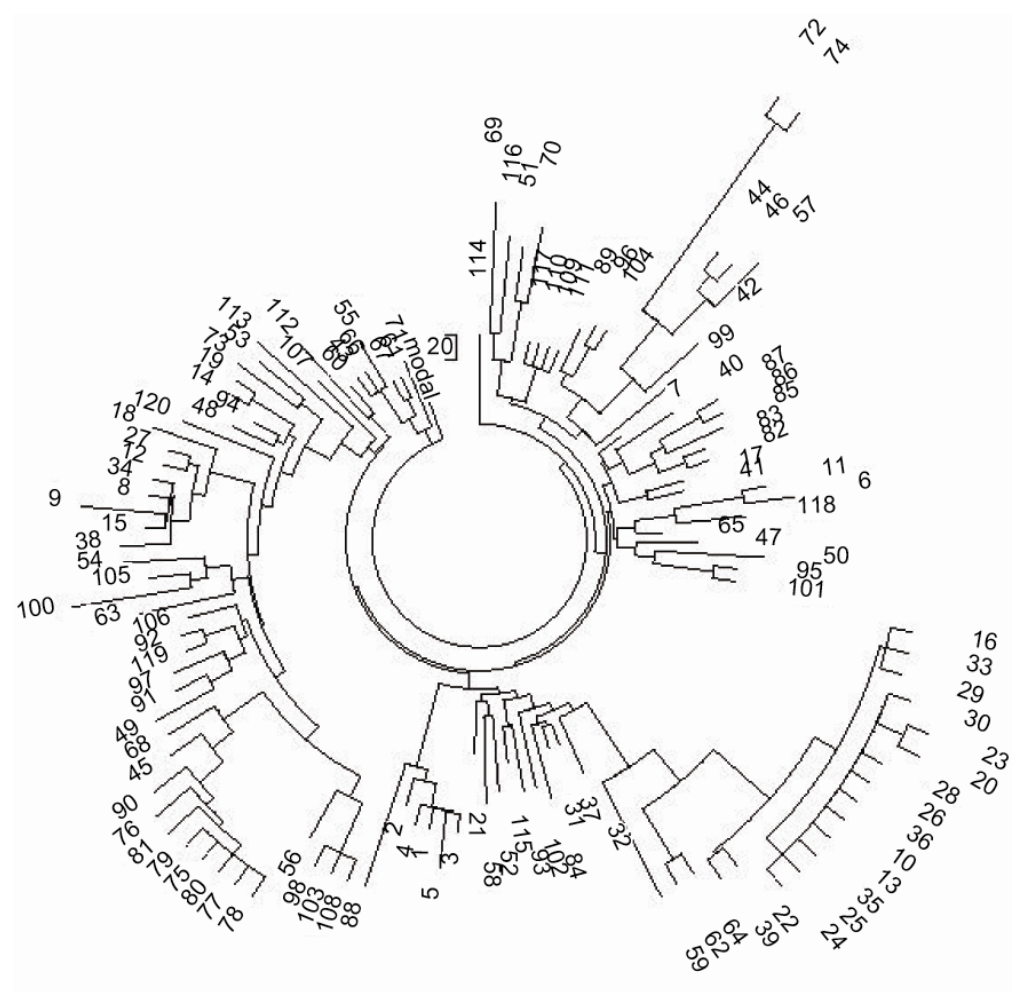

R-M269

Figure 9.

The 17-marker tree composed with 120 haplotypes of the R-L23 haplogroup, except five haplotypes of the M269 subclade (numbers $1-5$ ). The tree is composed based on data in (Herrera et al., 2011).

a high percentage of R1b haplogroup is very unusual in South Mesopotamia. According to the Assyrian FTDNA Project (see Appendix) half of their R1b bearers belong to R-L23 subclade with DYS393 $=12$, and all nine 12 marker haplotypes have 35 mutations, which gives 35/9/.02 =194 $\rightarrow 240$ conditional generations, or $6000 \pm 1200$ years to their common ancestor. Only 6 haplotypes were available in the 25 marker format, and they have 48 mutations; they yield 48/6/.046 $=174 \rightarrow 211$ generations, or $5275 \pm 930$ years. Those are indeed Sumerian times (e.g., Kramer, 1971). Most of the bearers of those haplotypes now live in Iraq and Turkey. Another half of the Assyrian haplotypes in the Project, mostly from Iran, have a slightly mutated "classical" European R1b1a2 base haplotype (with DYS464 = 151517 17), and a common ancestor of $850 \pm 360 \mathrm{ybp}$ calculated from the first 12 markers, and $1100 \pm 280 \mathrm{ybp}$ from the first 37 markers. This R1b evidence is clearly a relatively recent event in Assyrian population, brought from Europe.

The R-L23 subclade is clearly traced from the Russian Plain south via the Caucasus, where it prevails among R1b haplotypes, and via Anatolia, where it is very pronounced; down to South Mesopotamia, where Sumers had lived between 6000 and $4500 \mathrm{ybp}$ (Kramer, 1971). Since timespans to common ancestors of those R-L23 haplotypes are around 6000 - 5000 ybp, it is quite likely that those common ancestors lived among the Sumers and their ancestors (in the Caucasus and Anatolia). It might be an additional feature for linguists, some of whom consider Sumerian as a remnant of a subgroup of the DeneCaucasian language superfamily (e.g., Bengtson, 1997).

\section{Migrations of the Arbins from the Pontic Steppes, Asia Minor and Middle East Westward to Europe}

In the descriptions above we left bearers of R1b haplogroup in the Caucasus/Russian Plain/Pontic steppes, Anatolia, and Lebanon/Southern Mesopotamia around 6000 - 5000 ybp. All three areas were the relay regions for the Arbins to move further westward. Haplotypes of their present day descendants serve as the tracers of those ancient migrations.

A dataset of R1b1a2 haplotypes on the Balkans was published in (Barac et al., 2003a, 2003b; Pericic et al., 2005, and private communications with $\mathrm{M}$. Pericic). It contains a series of obviously R-L23 haplotypes with a base 122414111115 X X $\mathrm{X} 1313$ 29, and a common ancestor of $4050 \pm 890 \mathrm{ybp}$ (Klyosov, 2010c). Another series of the Balkan R1b1a2 has the base 132414111111 X X X 1413 29, with a common ancestor of $4975 \pm 1300 \mathrm{ybp}$ (ibid). Four mutations between them (including multi-copy mutations counted differently) place their common ancestor at $\sim 7000$ ybp to the time of ancient R-M269 haplotypes of the Russian Plain's (or further to the east). Migrations westward from the Pontic steppes are supported also by multiple archaeological evidences, which include those dating to the $3^{\text {rd }}$ millennium BC (e.g., Mallory, 1989).

The haplotype tree shown in Figure 8 provides some clues regarding possible directions of those ancient migrations. $40 \%$ of all 107 haplotypes of the tree belong to the Armenians and Turks; of those, $70 \%$ are haplotypes on the right-hand (larger) part of the tree. The upper left branch in the tree contains haplotypes from Russia, Lithuania, Poland, Croatia and Ireland. 
They all have the same pattern of mutations, with the base haplotype

$$
\begin{aligned}
& 122414111114121212121329 \text { - } 16910111125 \\
& 15193114151618 \text { (L23, mainly Eastern Europe) }
\end{aligned}
$$

which differs from the base haplotype of the left-hand side 38-haplotype branch by three mutations (marked; some alleles are fractional). This places their common ancestor with the entire branch at $4600 \mathrm{ybp}$. This indicates that the above largely East-European branch split from the sizeable branch at the Russian Plain in the middle of the $3^{\text {rd }}$ millennium BC and apparently migrated westward. That is one migration route (out of several described) which explains how R-L23 haplotypes appeared in Europe during those times.

Another migration route took place from the Russian Plain southward, as indicated by another quite distinct branch on the opposite side (at 5 o'clock) of the haplotype tree. The branch includes haplotypes from Russia, Lithuania, Armenia (two haplotypes), Turkey (three haplotypes), Syria. The base haplotype is as follows:

\section{$122414111114121212131330-16910111125$ $15192815151617 \quad$ (L23, mainly South)}

There are five full mutations between these two base haplotypes of the branches, both which includes Russian and Lithuanian haplotypes, albeit, with a principally different history. One group of L23 bearers went west to Europe; another went south to the Caucasus and the Middle East. They are separated by $5 / .046=109 \rightarrow 122$ generations, or by 3050 "lateral" years (this time is required on average to make five mutations in the 25 marker haplotype). In other words, these two branches show a fork in migration routes of R-L23 from the Russian Plain, westward and southward.

One additional branch of R-L23 includes haplotypes from Armenia, Lebanon, Bulgaria, Italy, France, Spain, Germany. It is located at 7 o'clock on the haplotype tree in Figure 8. Their base haplotype

\section{9 - 16910111125 \\ $15192915161618 \quad$ (L23, South and South-West)}

differs from the preceding discussed branch by only 2.6 mutations or by 1550 "lateral" years. This points to R-L23 movement from the Middle East westward to Europe. Its neighboring branch, including haplotypes from Turkey (three haplotypes), Greece and Albania evidences nearly the same base haplotype as the above, with only one mutation $12 \rightarrow 13$ in the first allele (DYS393) and $18 \rightarrow 17$ (17.3 on average) in the last allele. It is essentially the same migration route from Asia Minor to Europe. In fact, the entire right-hand large branch in Figure 8 consists of sub-branches with predominantly Armenian and Turkish (some Iraqi and Iranian) R-L23 haplotypes with singular inclusions of haplotypes from Greece, Germany, Netherlands, England, Scotland. This reflects migration routes of the Arbins from Asia Minor and the Middle East to Europe mainly between 4500 and 3500 ybp.

It may be expected that some migrations from the Middle East to Europe are associated with this mutation of DYS393 12 $\rightarrow 13$ in the subclade R-L23. However, other, later migrations, could have occurred from the European continent eastward, and belong to more recent subclades, such as L51, L11, P312, U106, L21, U152, etc. (Klyosov, 2011b). Indeed, most Sardinian hap- lotypes have DYS393=13, such as the following base haplotypes on Sardinia (calculated from data provided in [Contu et al., 2008]):

\section{$132414111114 \times$ X X $13 \times 29$}

$132414101114 \times$ X X 13 X 29

132414101115 X X X 13 X 29

The first one was presented on the tree by a series of identical haplotypes which are obviously derived from the very recent common ancestor (Klyosov, 2008a, 2010c). They are indistinguishable from common European R1b1a2- M269 subclades, such as R-P312, R-L21, R-U152, R-L2, R-L20, etc. The second one has a timespan to its common ancestor of $3550 \pm$ $790 \mathrm{ybp}$, the third descended from a common ancestor who lived $2900 \pm 620 \mathrm{ybp}$. A common ancestor of all of them lived $5025 \pm 630 \mathrm{ybp}$, which fits the time and direction of ancient migration of the Arbins from the Middle East to Europe (however, DYS393 = 13 would be unusual for them), and from Iberia up north to the continent, and subsequently populating Europe in all possible directions.

One of the most common R1b base haplotypes in Sicily is as follows (Di Gaetano et al., 2009): 132414111114 X X 1213 1329 , which is identical to one of the Sardinian base R1b haplotypes above, and indistinguishable from common R1b subclades in Europe. The timespan to a common ancestor for that haplotype in Sicily calculated from the cited study is $4550 \pm$ 1020 years. The same base haplotype is the most common in Italy (Capelli et al., 2007), with a timespan to the common ancestor of $4125 \pm 500$ years calculated by the linear method, and $4300 \pm 1160$ years calculated by the logarithmic method (Klyosov, 2008a).

There is one more, but very important migration route of the Arbins which does not practically include R-L23 haplotypes (only 5\% of DYS393 = 12 among Iberian R1b haplotypes, it corresponds to a random mutation from the parent DYS393 = 13). It is a route from the Middle East westward along North African Mediterranean seacoast. R-L23 was either not represented or did not survive along this route. It seems that bearers of R-V88 were part of the journey, however, split and went southward and settled in Central Africa (mainly Cameroon and Chad), mentioned previously. The migration of the Arbins from the Middle East to the Atlantic, then across the Strait of Gibraltar to the Pyrenees took place from $\sim 5500-5200$ ybp to 4800 ybp when the Arbins landed in Iberia (see supportive references to archaeological data below). Part of the way from Egypt to Iberia could have been made by sea, details are not known as yet. There are some historical reports of arrival of the Egyptian military fleet to Iberia some $5000 \mathrm{ybp}$; there are some allegedly Egyptian mummies and fragments of Egyptian tombs exhibited in the Royal Academy of History in Madrid and in the Tarragona City Museum. Their status, however, is rather vague. It seems, nevertheless, that bearers of R1b subclades, mainly R-M269, and newly formed L51 and L11 (see below) had arrived in Iberia and this was the beginning of the archaeological Bell Beaker culture.

Previous to discussing the Bell Beakers and history of the Arbins in Europe, it is worth mention of one more rather vague evidence of the R1b journey via ancient Egypt between 5500 and 5200 ybp. It concerns the alleged R1b haplotype of Pharaoh Tutankhamun. 


\section{Alleged Pharaoh Tutankhamun R1b1a1-M269* Haplotype and Its Possible History}

Recently the Swiss company iGENEA has published the alleged 16 marker haplotype of the Pharaoh: $132414111114 \mathrm{X}$ X 10131330 - 161419101512

(www.igenea.com/en/ index.php?c=62).

Here the first 12 markers are shown in the FTDNA format, and the rest are DYS 458, 437, 448, GATA H4, DYS 456, 438. It is obviously not a typical European R1b1a2 haplotype, since it has DYS439 = 10, and not a common European 12. There are only about $0.5 \%$ R1b haplotypes in Europe with DYS439 $=10$. The most likely and the most closely related base haplotype is that of R1b1a2-M269, shown in Figure 5, in which the same markers as those available in the Pharaoh haplotype are noted in bold:

122514111114111212131329 - 17910111125

$15192915151617-1011192315151917353812$

12 - 1191516810108111012232316101212158

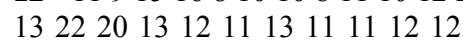

(M269)

There are 6.8 mutations between the two 16 marker haplotypes (some alleles in M269 haplotype are fractional), which translates to $6.8 / .0315=216 \rightarrow 274$ conditional generations, or 6850 years between them. Since Tutankhamun lived 3300 ybp, and the R-M269 base haplotype is $6200 \pm 900$ years "old", then a common ancestor of the two lived $(6850+6200+3300) / 2=$ 8175 ybp. This might have been either an ancient R-M269 ancestor of the Tutankhamun from Central Asia, or the respective upstream subclade.

The main point here is that the Pharaoh haplotype is not some erroneously (or intentionally) picked European R1b1a2 haplotype; it is an archaic haplotype of R1b haplogroup, likely of the R-M269 ancient subclade.

It should be mentioned here that the founder of the Egyptian pharaohs was Narmer, the origin of whom is not firmly known, and was the founder of the First Dynasty, living ca. $32^{\text {nd }}$ century $\mathrm{BC}$ - around $5200 \mathrm{ybp}$. This date fits the migration times for the Arbins along the Mediterranean coast in North Africa. It cannot be excluded that the bearers of R1b haplogroup may have actually established the Royal lineage in ancient Egypt. It does not mean that the lineage was not interrupted through the Dynasties; however, it kept returning into the Dynasties, if the $\mathrm{R} 1 \mathrm{~b}$ origin of some Pharaohs is right.

\section{The Overview of the Migratory Path of the Arbins, Bearers of R1b Haplogroup, from Central Asia to Europe}

An overall map of R1b migration routes from the very "beginning", where "beginning" is undefined in detail thus far and can be estimated between 16,000 and 12,000 ybp, and until their arrival to the Pyrenees by 4800 ybp as future Bell Beakers, is shown in Figure 10. Their migratory path was slowly taking place from Central Asia, apparently from Altay, South Siberia, when some very different R1b haplotypes were discovered. As it is described in the first sections of this paper, their tremendous mutational difference with European and Middle Eastern R1b haplotypes places their common ancestors at $\sim 16,000 \mathrm{ybp}$.

The legend to Figure 10 describes those Central Asian/Siberian populations. There are many Neolithic, Chalcolithic and Eneolithic archaeological cultures in the area, such as Tersek,
Ural, Surtandi, Mahandzhar, Iman-Burluk, Botai, Atbasar, Kelteminar, and other archaeological Central Asian cultures in present-day Russia (e.g, Zakharov, 2010), which might be assigned to the Arbins; however, it would be premature to assign any of them to R1b or to any other haplogroup. Such a task is quite new for archaeologists. It is tempting to point at Seroglazovo, Khvalyn, Samaran, Middle-Volga and adjacent archaeological cultures of 12,000 - 5000 ybp of the European Russian east as the most likely R1b cultures. We cannot, however for the same reason of prematurity and it would be irresponsible to suggest such at this time. The same may be said for Yamnaya, Catacomb and neighboring archaeological cultures of Central and South Russia, which apparently were shared by both R1b and R1a bearers, albeit in different time periods. R1b before $5000 \mathrm{ybp}, \mathrm{R} 1 \mathrm{a}$ after $4500 \mathrm{ybp}$ have confused archaeologists who have observed "different roots" of those cultures, spreading in different directions and in different times.

The map shows that current bearers of R1b spread over Central Russia up to Arkhangelsk on the White Sea. Very likely it was a relatively recent relocation although it remains to be determined. Currently there are only about $5 \%$ of R 1 b bearers in the European part of Russia.

As it was described above in this study, the Arbins went South through the Caucasus to Mesopotamia and the Middle East around 6000 - $5000 \mathrm{ybp}$; established the Sumer civilization; went westward via Egypt to the Atlantic, and across the Gibral$\operatorname{tar}$ Strait to the Pyrenees. On their way some R1b-V88 bearers split; went deep into Africa, and currently populate Cameroon and Chad in appreciable amounts (see legend to Figure $\mathbf{1 0}$ and description and references above). By 4800 ybp the Arbins have reached Iberia to become the first Bell Beakers. This date was obtained for a common ancestor of haplotypes of P312 and U106 subclades (see the next Section), and is supported by archaeology data (Cardoso \& Soares, 1990; Martinez et al., 1996; Cardoso, 2001; Muller \& Willigen, 2001; Nocete, 2006).

\section{Several Entry Routes of R1b1a2 Haplotypes to Europe: From the Russian Plain, from Asia Minor/Middle East, from the Pyrenees}

To sum up the preceding section, the Arbins were entering Europe from the east by several routes: from the Russian Plain (between the Pontic Steppes and the Baltic Sea); from Asia Minor and the Middle East; and after a long way around Mediterranean Sea to Iberia, up north to the European continent. The first two principal routes were associated with bearers of the R-L23 subclade. The Iberian route was made by mainly M269 which at the time of entering the Pyrenees split R-L51 and immediately after R-L11. Both are very similar and have very close timespans to their common ancestors, as it is shown in the next section. In 4850 ybp L11 promptly split off two "brother" subclades, P312 and U106 (Klyosov, 2011b) which after a long "population bottleneck" on the edge of extinction, eventually survived and expanded around 4000 - $3700 \mathrm{ybp}$, and actively populated Europe, first as Bell Beakers, between 4000 and $3000 \mathrm{ybp}$, and then up to the era of Ancient Rome, Gauls and Celts, mentioning only those names which present certain "milestones" in history. In fact, there were dozens if not hundreds of ancient R1b tribes in Europe. 


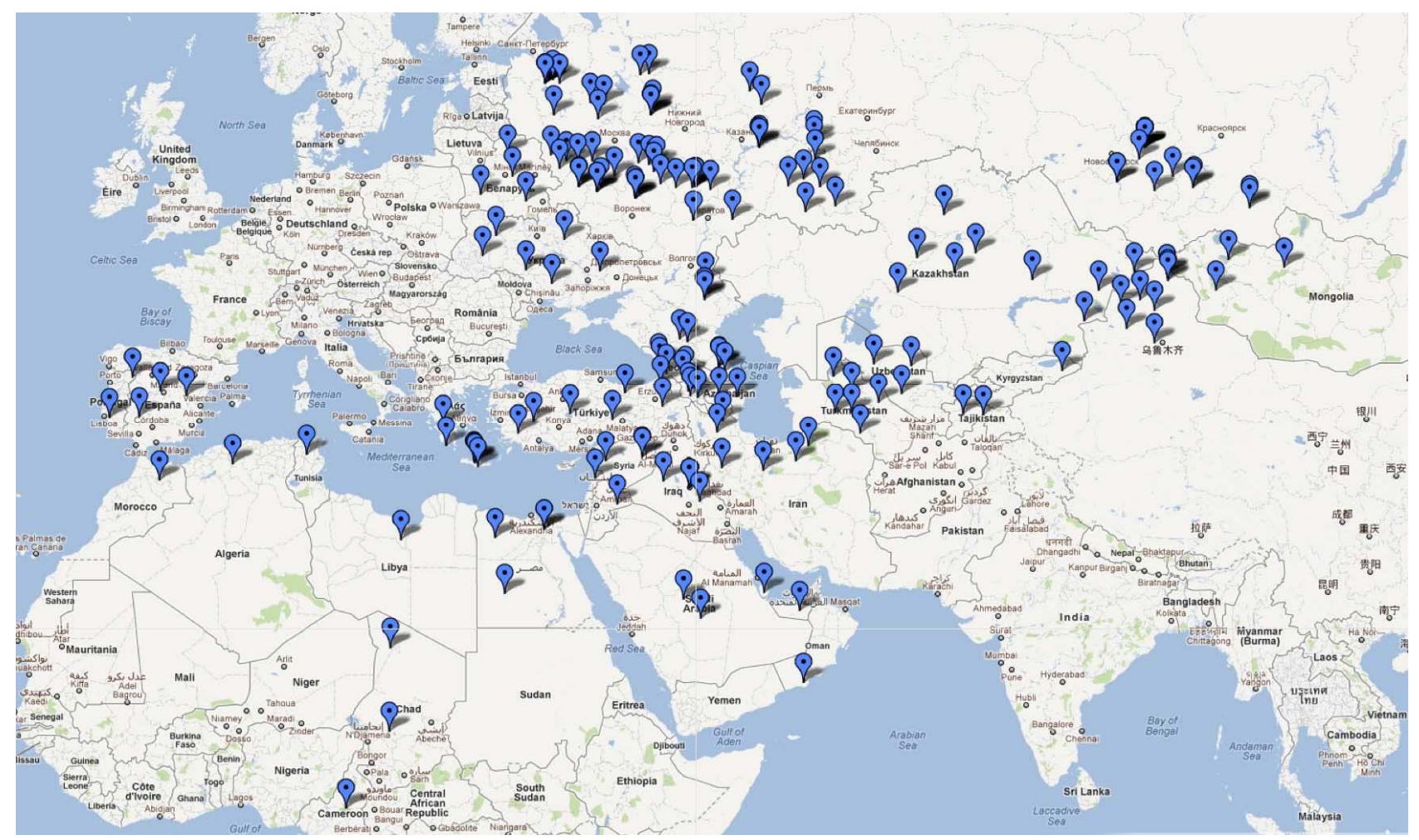

Figure 10.

The map of R1b haplotype locations considered in this study, until they arrived to Iberia $\sim 4800 \mathrm{ybp}$. The overall migration path of the Arbins had apparently started in South Siberia, where present day R1b haplotypes of the Shors, Teleuts, Altayans, Uighurs, Khakass, Tuva people (the right-hand side pins) are tremendously different from those in Europe and the Middle East. The migration route continued through the regions in Middle Asia and Russia, where Bashkirs, Kazakhs, Uzbeks, Mari, Tatars, Kalmyks presently live. From the Central Russia region the Arbins moved to the Caucasus and further South to Anatolia, Middle East, present day Iraq, Lebanon, and then westward along the Mediterranean Sea onto Northern Africa to the Atlantic. On that way R1b-V88 bearers split and went deep into Africa, where their descendants currently live in Cameroon and Chad (Cruciani et al., 2010). Their migratory path into Africa is reproduced here from the above reference. The map shows R1b locations previous to arrival to the Pyrenees $\sim 4800 \mathrm{ybp}$, from where they moved North as Bell Beakers and populated Europe between $4800-3000$ ybp and later.

\section{Main R1b1a2 Subclades on the European Continent: Entering Europe 4800 - 4500 ybp from the East and from the South West}

Nearly all haplotypes of the subclade R-M269 6000 - 5000 ybp belonged either to R-M269* para-group, or to its downstream subclade R-L23. The Arbins who had migrated from the east to Europe during those times mostly carried DYS393 $=12$. Currently we see only those R1b1a2 (xL23) haplotypes in Europe, which are derived from common ancestors who lived a maximum $\sim 4500$ ybp. Either descendants of more ancient L23 ancestors have not survived into the present time or there were none from the eastern Russian Plain, Asia Minor, and the Middle east.

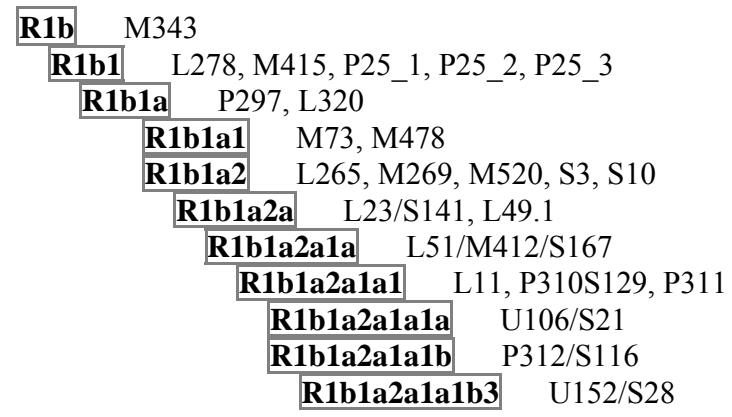

\begin{tabular}{|c|c|}
\hline R1b1a2a1a1b4 L21 & /M529 \\
\hline R1b1a2a1a1b4b & M222 \\
\hline R1b1a2a1a1b4g1 & \\
\hline R1b1a2a1a1b4h1 & \\
\hline
\end{tabular}

The above diagram shows that the immediate downstream subclades of R-L23 were L51 and then L11 (ISOGG-2012, in an abbreviated form). The dynamics of these subclades is much more understood via Iberia into the continent where the migration of the Arbins is being identified with the Bell Beakers.

The question is - where those L51 and L11 subclades could have arisen? If they are 6000-5000 years "old", they could have split in Asia Minor, the Middle East or on the Russian Plain, and enter Europe from there. The "intraclade" haplotypes, that is only L51 or only L11 subclade, might reflect population bottlenecks, hence, look "younger" than they in fact should be (in terms of mutations and the respective TMRCA). However, their "interclade" comparison could reveal their lost (due to bottlenecks) timespans to more ancient common ancestors. To analyze those subclades, a combined L51-L11 haplotype tree is shown in Figure 11.

One-third of haplotypes on the tree belong to the L51 subclade, and they occupy the right side. Another two-thirds are L11 haplotypes, which are on the left and make some "insert" branches on the right. The 67 marker haplotypes of L51 and 


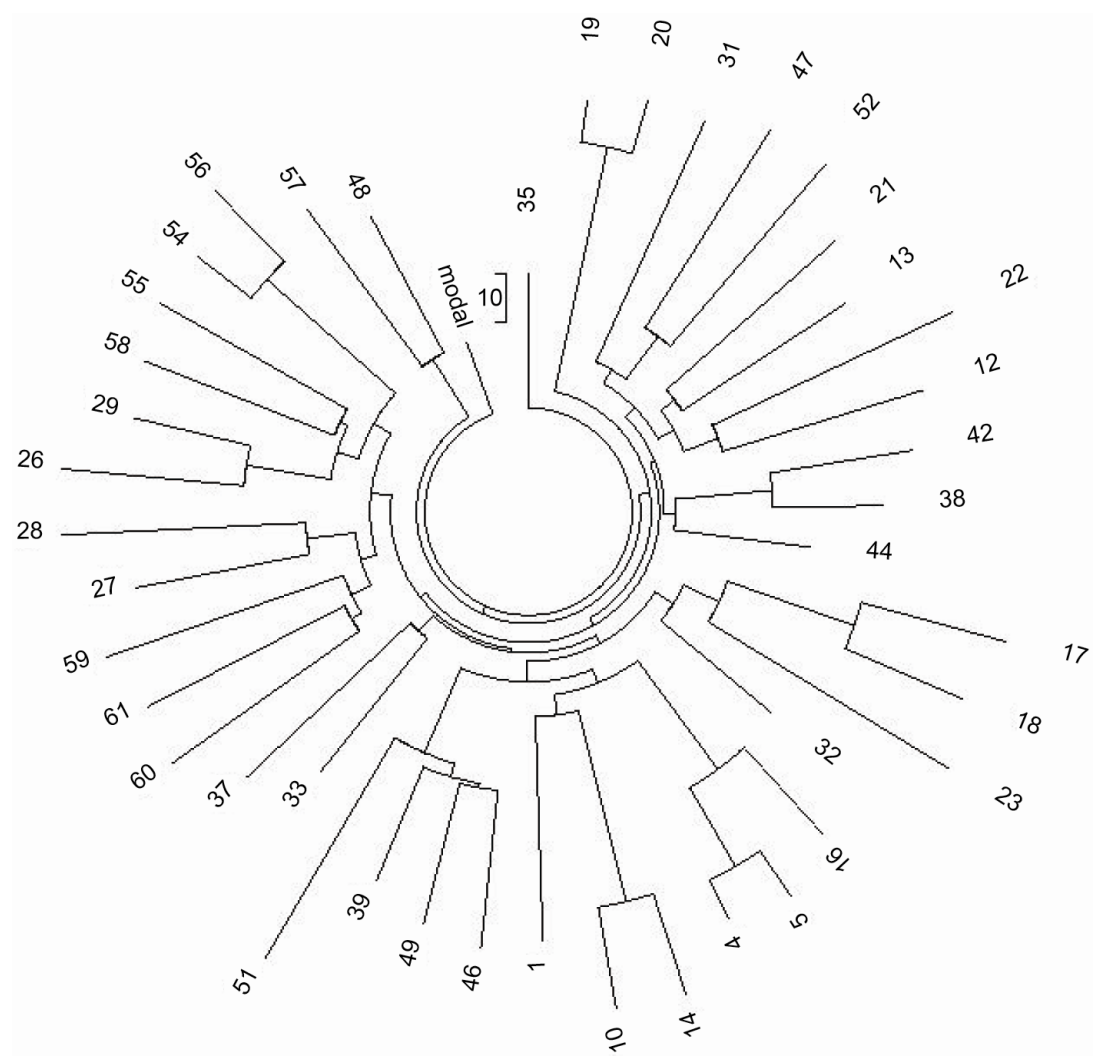

Figure 11.

The 67-marker tree composed with 42 haplotypes of the R-L51 subclade (15 haplotypes on the right, numbers between 1 and 23) and R-L11 (27 haplotypes on the left, numbers between 26 and 61). Haplotypes are listed in the FTDNA public Project

http://www.familytreedna.com/public/ht35new/default.aspx.

L11 subclades are very similar, therefore the tree could not distinguish them in a number of cases; hence, the mix of the branches. The tree also shows that the "age" of the two subclades is also very similar, since the "height" (which generally indicates the "age") of the branches around the tree is about the same. The base haplotype of R-L51 subclade is as follows

$$
\begin{aligned}
& 132414111114131212131329 \text { - } 17910111125 \\
& 15193015161718-1111192316151817363812 \\
& 12 \text { - } 1191516810108101012232316101212168 \\
& 1222201412111311111212
\end{aligned}
$$

It deviates from the base R-L23 haplotype (5400 $\pm 800 \mathrm{ybp})$ by 9 mutations (12 mutations are marked above, but many of them are fractional), that is by $9 / .12=75 \rightarrow 81$ generations, or $\sim 2025$ years of the "lateral" distance. All 15 haplotypes contain 280 mutations from the base haplotype, which gives 280/15/.12 $=156 \rightarrow 184$ generations, or $4600 \pm 535$ years from their common ancestor, L51. In turn, it gives $(2025+5400+4600) / 2$ $=6000$ years, which is an "age" of a common ancestor of both L23 and L51 subclades. Obviously, it is the common ancestor of L23 subclade himself.

In other words, the "age" of the L51 subclade as $4600 \pm 535$ years is obtained from mutations on the L51 branch on the tree (Figure 11) and confirmed 1) by a mutational distance from the base haplotype of the parent L23 subclade, 2) by the "age" of the L23 subclade, determined earlier, and 3) by the general phylogeny of the R1b subclade. The "age" of the L51 subclade fits well with the arrival time of the Arbins to Iberia (4800 ybp), to the distribution pattern of the current bearers of L51 in Europe (the highest frequency is in the Pyrenees and immediately up north in France and on the Isles, see [Myres et al., 2010]. It is practically absent in European South-East, East, and North-East (ibid.).

Analysis of the L11 subclade is more complicated since its haplotypes are spread around the tree by at least four branches, each with its common ancestor. They differ from each other by 32 mutations which gives $32 / 4 / .12=67 \rightarrow 72$ generations, or 1800 years below their average "age" $\sim 2500$ years. Therefore the "age" of the R-L11 subclade is $\sim 4300$ years, which is indeed consistent with $4600 \pm 535$ years for the L51 subclade. The base haplotype for the L11 subclade is as follows:

132414111114121212131329 - 17910111125 $15193015151717-1111192316151817363812$ 12 - 1191516810108101012232316101212158 1222201312111311111212

Five deviations between them (marked in bold) present in fact 3.7 mutations (since most of them are fractional), which gives $3.7 / .12=31 \rightarrow 32$ generations; that is only 800 "lateral" years between them. This confirms that L51 and L11 subclades are very close to each other in time. Their common ancestor (which presumably should be L51) lived $(800+4600+4300) / 2$ $=4850 \mathrm{ybp}$. It seems that L11 split off only $\sim 250$ years later. All of them are likely to have established the archaeological 
Bell Beaker culture. The oldest artifacts of the Bell Beakers were found in Portugal, dated 4800 - 4600 ybp (Cardoso \& Soares, 1990; Martinez et al., 1996; Cardoso, 2001; Muller \& Willigen, 2001; Nocete, 2006).

\section{Main R1b1a2 Subclades on the European Continent: Population of Europe after 4800 ybp, Main Subclades on the Isles and Their Likely Origin}

The phylogeny of R1b (see the diagram above) shows that the further downstream subclades of R-L11 are P312 and U106. Their 67 marker haplotypes are as follows:

132414111114121212131329 - 17910111125 $15192915151717-1111192315151817363812$ 12 - 1191516810108101012232316101212158 1222201312111311111212

(P312)

132314111114121212131329 - 17910111125 $15192915151717-1111192316151717373912$ $12-1191516810108101012232316101212158$ 1222201312111311111312

(U106)

There are 5.5 (marked in bold) mutations between them (DYS456 in P312 fluctuates between 15 and 16 in various datasets), which separates the two base haplotypes by $5.5 / .12=$ $46 \rightarrow 48$ generations, or by 1200 years. Since common ancestors of both subclades lived $4350 \pm 700$ and $4175 \pm 430 \mathrm{ybp}$ (Klyosov, 2011b), their common ancestor lived $(1200+4350+$ $4175) / 2=4850 \pm 700 \mathrm{ybp}$. Indeed, it is the "age" of the subclade L11 within margin of error. Generally, it is safe to accept the "age" of both P312 and U106 as $4200 \mathrm{ybp}$, since estimates, depending on a dataset, are fluctuating around this value. There is 1200 years between them (see above) which defines a timespan to their common ancestor, L11, as $(4200+4200+1200) / 2$ $=4800 \mathrm{ybp}$.

As it was stated above, the four subclades, L51, L11, P312 and U106 historically represent the first wave of Bell Beaker movement from Iberia to the European continent. The highest frequency of $\mathrm{P} 312^{*}$ subclade in Europe is currently observed in Iberia (Myres et al, 2010), however, it is naive to judge ancient locations of the subclades based on their current distribution. The mixing of them on the Continent has been too intense in the past millennia to make any unambiguous extrapolations. The current regional distribution of the R-M269's downstream subclades which moved from the Pyrenees nearly five millennia ago is classically non-informative, except in instances of some local subclades. One of them is R-M222.

It seems that the history of R-M222 appearance on the Isles may have began with seafaring carriers of $\mathrm{L} 11^{*}$ bearers from Iberia to the Isles some 4500 - $4000 \mathrm{ybp}$. However, it is just one theory. Other involve migrations of L21 bearers to the Isles by land. Then, P312, a downstream of L11, is also intensely represented on the Isles along with its downstream subclades, as well as its "brother" subclade U106 and its downstreams (ibid). L21, a downstream of P312, is abundant on the Isles, unlike its "brother" subclade U152 (ibid). This ancient migration of the Arbins from Iberia to the Isles explains some genetics data on the "Spanish origin of the Irish".

M222, a downstream of L21, is among the most represented R1b subclades on the Isles. A massive Ireland Heritage FTDNA project (see Appendix) lists several thousand of R1b (with sub- clades) haplotypes in the Isles, of which M222 is the largest, and includes about $25 \%$ of all R1b (Klyosov, 2010e). The subclade is expressed the most in Ireland. In Scotland it is observed mainly in the lowlands and in central region, and poorly presented in England. The base haplotype of the M222 subclade is:

132514111113121212131429 - 17910111125

$15183015161617-1111192317161817383912$

$12-1191516810108101012212316101212168$

1225201312111311111212

(M222)

It is of interest that the above base haplotype differs from the "brother" base haplotypes of P312 and U106 by 18 mutations in each case (in fact, 15 mutations, since some mutations are fractional). It shows that P312 and U106 are indeed very close (in time and in heritage) base haplotypes, and that their common ancestor, a bearer of L11 base haplotype, lived very close in time to both of them. 15 mutations place their common ancestor at $4600 \pm 500 \mathrm{ybp}$.

Multiple analyses of M222 haplotype datasets gave a timespan to its common ancestor of currently living M222 descendants of $1450 \pm 160$ years (Klyosov, 2010e). However, cross examination of a number of lineages in the M222 subclade has shown that the M222 lineage arose not later than in the beginning of the Common Era, some 400 years earlier than the above estimate. It points to a possible population bottleneck between the time when M222 arose, and the expansion of the subclade in the middle of the $1^{\text {st }}$ millennium CE. One cannot possibly say, at least yet, where specifically the M222 subclade first appeared (that is, the $\mathrm{G} \rightarrow$ A single nucleotide mutation occurred in certain nucleotide of $Y$ chromosome of a certain individual, the bearer of the upstream L21 subclade), whether in the Isles, in North Western Europe, or elsewhere. We also cannot determine specifically against what R-M222 direct descendants have been struggling for survival for several centuries. Was it a long climatic event? The Roman invasions? Epidemics? Famine? or a combination? We know, however, that it was the Isles where this mutation on the Y chromosome was eventually carried on and flourished.

The phylogenic diagram shows that the M222 mutation arose concurrently with its "brother" SNP mutations which now define subclades L226 and P314. The first one has a common ancestor who lived $1500 \pm 170 \mathrm{ybp}$, which is at the same time with that of M222, albeit in L226 the subclade-defined mutation was $\mathrm{C} \rightarrow \mathrm{T}$. Its base haplotype is as follows:

132414111114121211131329 - $17 \mathbf{8 9} 11112515$

192913131517 - 111119231515181736381212

- 119151681010810101223231510121215812 $\begin{array}{llllllllll}22 & 20 & 13 & 12 & 11 & 13 & 11 & 11 & 12 & 12\end{array}$

(L226)

It differs by as many as 21 mutations from its "brother" M222 subclade, despite the observation that their common ancestors lived at the same time. It only confirms that their common ancestor, the founder of subclade L21, lived around $4100 \mathrm{ybp}$. It also shows that L21 formed almost immediately from P312 (see the phylogenic diagram) since P312 arose 4350 - 4200 ybp and L21 around 4100 ybp. Their 67 marker haplotypes are identical, within some fractional mutational difference:

132414111114121212131329 - 17910111125

$15192915151717-1111192315151817363812$

$12-119151681010810101223231610121215$ 
81222201312111311111212

(P312)

132414111114121212131329 - 17910111125 $15192915151717-1111192316151817363812$ 12 - 119151681010810101223231610121215 81222201312111311111212

The only apparent difference, in DYS456, is also fractional, since this allele fluctuates in P312 between the values of 15 and 16.

Despite their similar chronology, subclades M222 and L226 have quite different histories for the preceding 2600 years. Yet another "brother" subclade, P314 (more accurately, P314.2, since the same P314 SNP mutation, $\mathrm{T} \rightarrow \mathrm{C}$, has occurred in haplogroup H2a), is somewhat "older", with its $2225 \pm 300 \mathrm{ybp}$; however, it could be within the same time frame when M222 actually arose. Its base haplotype

$132314111114121313131329-17910111126$ $15192915151617-1011192316151818373812$ 12 - 119161681010811101223231710121215 81222201312111311111212

(P314.2)

is again remote from those of M222 and L226 subclades, by 24 and 17 mutations, respectively. It is a third, completely different lineage in the L21 family. The 10 full mutations from its L21 parent base haplotype gives $10 / .12=83 \rightarrow 91$ generations, or 2275 years of the mutational difference, and places the beginning of the L21 subclade at $(2275+4100+2225) / 2=4300$ years, which is within margin of error from 4100 years estimated above. All these base haplotypes along with the intraclade and interclade datings form a rather robust system of DNA genealogy of the Arbins in Europe and Asia.

\section{Materials and Methods}

Four thousand four hundred eight (4408) of R1b haplotypes (with subclades) were collected in databases from FTDNA, YSearch, and in peer review publications.

The methodology of haplotype datasets analysis was described in the preceding publication in this journal (Rozhanskii \& Klyosov, 2011). In this study the linear and the logarithmic method were employed; the latter when the base haplotype in the dataset was easily identifiable, as described in (Klyosov, 2009c). The mutation rate constants are listed in (Klyosov, 2009c; Rozhanskii \& Klyosov, 2011), and for a number of cases are given in the text of this paper. The most widely used mutation rate constants, including those employed in this paper, are as follows (in a number of mutations per haplotype per the conditional generation of 25 years); the references show examples of the haplotypes in the format indicated:

.013 , the 8 marker haplotype (Zhong et al.)

017, the 8 marker (Contu et al.)

.018 , the 10 marker (Myres et al.)

.020 , the 11 marker (Cruciani et al.)

.019 , the 11 marker (Zalloua et al.)

020, the 12 marker FTDNA format

.024 , the 12 marker (Malyarchuk et al.)

.034 , the 17 marker Y-filer format (Herrera)

.035 , the 19 marker (Balanovsky et al.)

.046 , the 25 marker FTDNA format

.090 , the 37 marker FTDNA format

120 , the 67 marker FTDNA format
.198 , the 111 marker FTDNA format

FTDNA haplotype formats are given in http://www.familytreedna.com/faq/answers.aspx?id=9

Haplotype trees were composed using software PHYLIP, Phylogeny Inference Package program (see Klyosov, 2009c, 2009d and references therein). Corrections for back mutations were introduced as described in (Klyosov, 2009c). Margins of error were calculated as described in (Klyosov, 2009c).

Base haplotypes in the dataset were determined by minimization of mutations; by definition, the base haplotype is one which has the minimum collective number of mutations in the dataset, derived from one common ancestor. The base haplotype is the ancestral haplotype or the closest approximation to the latter.

A timespan to the common ancestor of two base haplotypes is determined as follows: 1) count the number of mutations between the two base haplotypes, 2) divide the obtained number by the mutation rate constant, 3) introduce a correction for back mutations, calculated using the following formula (Klyosov, 2009c):

$$
\lambda=\frac{\lambda_{\text {obs }}}{2}\left(1+\exp \left(\lambda_{\text {obs }}\right)\right)
$$

where:

$\lambda_{\text {obs }}=$ observed average number of mutations per marker in a dataset (or in a branch, if the dataset contains several branches/ lineages).

$\lambda=$ average (actual) number of mutations per marker corrected for back mutations, 4) add the obtained value, multiplied by 25 (years), which represent the "lateral" timespan between times of appearance of the two base haplotypes, to TMRCAs for the both base haplotypes and divide by 2 . The result represents the TMRCA (time for the most recent common ancestor) for the two base haplotypes under study. The following examples are based on specific cases in this study.

Example 1: Calculation of a timespan to a common ancestor of the branch (the most remote on the haplotype tree shown in Figure 1) which contains 12 of eight marker haplotypes collectively having 65 mutations from their base haplotype. Since the mutation rate constant for these haplotypes equal to 0.013 per haplotype per a conditional generation ( 25 years), we have $65 / 12 / .013=417 \rightarrow 619$ generations, that is $619 \times 25=15,475$ years to a common ancestor of the branch. The arrow shows a correction for back mutations. This correction can be calculated using a formula (1) as follows. Since the observed number of mutations per marker is $65 / 12 / 8=0.677$, we employ formula (1) and obtain

$$
\frac{1}{2}(1+\exp (0.677)) \lambda_{\text {obs }}
$$

The obtained number of 1.484 is the coefficient of the correction for back mutations. Therefore, by multiplying $417 \times$ 1.484 , we obtain that the corrected number of generations is 619 , that is $619 \times 25=15,475$ years. This is usually designates as $417 \rightarrow 618$ (generations). Since for 65 mutations in the dataset the margin of error is $15.93 \%$ (calculated as explained in Klyosov, 2009c), we at last obtain the timespan to a common ancestor of the haplotypes to be equal to $15,475 \pm 2500$ years.

Example 2: Two 67 marker base haplotypes of subclades R-P312 and R-U106 differ by 5.5 mutations (see the text above). Applying the same rule explained in the preceding ex- 
ample, we get $5.5 / .12=46 \rightarrow 48$ generations, that is 1200 years from a common ancestor of the two base haplotypes (that is, of the two subclades). Should the two base haplotypes have the same "age" (the same TMRCA), their common ancestor lived 600 years "deeper" in time from either one of them. However, in this particular case the two TMRCA are equal to 4350 and 4175 years, respectively. Therefore their common ancestor lived $(1200+4350+4175) / 2=4850$ years ago.

\section{Conclusion}

The results of this study lend a support to the theory that haplogroup R1b arose in Central Asia, apparently in South Siberia or the neighboring regions, around 16,000 years before present. The preceding history of the haplogroup is directly related to the appearance of Europeoids (Caucasoids) $\sim 58,000$ ybp, likely in the vast triangle that stretched from Western Europe through the Russian Plain to the east and to Levant to the south, as it was suggested in (Klyosov, 2011d). A subsequent sequence of SNP mutations in Y chromosome, with the appearance of haplogroups NOP $\sim 48,000 \mathrm{ybp}$ and $\mathrm{P} \sim 38,000$ ybp in the course of their migration eastward to South Siberia, eventually gave rise to haplogroup $\mathrm{R} \sim 30,000 \mathrm{ybp}$ and $\mathrm{R} 1$ $\sim 26,000 \mathrm{ybp}$, and then to haplogroup R1a/R1a1 20,000 ybp (the timeframe between the appearance of R1a and R1a1 is uncertain) and R1b 16,000 ybp (ibid.).

Based on the respective syllables, we call bearers of R1a the Aryans, and those of R1b the Arbins. In the first case that name is justified since the bearers of the R1a haplogroup became the legendary Aryans who arrived in the Hindustan and Iranian Plateau $\sim 3500$ ybp. In other words, those Aryans belonged to R1a haplogroup, hence, the double meaning (albeit coinciding) of the term the Aryans. The Arbins is a convenient common term in avoidance of the repetition: "The bearers of haplogroup R1b".

At some point in time, the Arbins began migration to the west, across Central Asia, North Kazakhstan, South Urals, to the Russian Plain where they have established a number of archaeological cultures between 12,000 and $4500 \mathrm{ybp}$ (includeing apparently Seroglazovo, Khvalyn, Samaran, Middle Volga, Drevneyamnay, Catacomb, and also "Proto-Kugran" and/or "Kurgan" cultures which are largely considered as controversial and not accepted by many historians; it should be emphasized that all those above suggestions regarding the archaeological cultures can be viewed at present only as very tentative ones). They migrated southward, in part (leaving their R1b haplogroup and the respective haplotypes behind), over the Caucasus to Anatolia around $6000 \mathrm{ybp}$; to the rest of Asia Minor, and to the Middle East. The Arbins have apparently established the Sumer culture and the state and migrated westward to Europe by several routes, carrying mainly the R-M269 subclade and its downstream L23 subclade. One route is the northern route, from the Russian Plain to the west, 4600 - 4400 ybp; another, concurrently along Asia Minor and the Middle East westward with the same two subclades; and yet another which will populate Europe the most, migrating along North Africa-Mediterranean Sea via ancient Egypt to the Pyrenees, to arrive $\sim 4800$ ybp. On this route the R1b-V88 tribe split off and went south, eventually to Central Africa (mainly Cameroon and Chad judging by their present-day distribution), where a common ancestor of the current R1b-V88 haplotype lived $\sim 4400 \mathrm{ybp}$.

At the arrival time to Iberia $\sim 4800 \mathrm{ybp}$, the M269 subclade split off M51 and soon thereafter L11 and its downstream subclades. They became the Bell Beakers and moved north along with newly arisen subclades P312 and L21, the latter within a few centuries after P312. Those subclades and their downstream clades have effectively without major interruptions populated Europe from the Atlantic to the Balkans, Carpathian Mountains, present day Poland, the western border of the Russian Plain, to the Baltic Sea evidenced by the smooth haplotype trees as witness to non-stop proliferation of R1b haplotypes.

The Isles had a different history of their R1b haplotypes and lineages. The bearers of L11, P312 and L21 moved to the Isles by land and sea concurrently with those Arbins who were populating Europe between 4000 and $2500 \mathrm{ybp}$, and formed the respective "local" subclades, such as P314, M222, L226, which largely populated the Isles. As a result, a significant part of the Isles is populated almost exclusively by the Arbins whose frequency reaches $92 \%-96 \%$ among the population. In general, the frequency of the Arbins in Western and central Europe reaches - albeit not uniformly-some $60 \%$ of the population.

This study essentially presents an example of the application of DNA Genealogy for studying the history of mankind. This example is a complex and challenging endeavor which also touches upon some mysterious puzzles of history and linguistics. One of those puzzles is what language or languages were spoken by the Arbins from 16,000 to $3000 \mathrm{ybp}$ and it almost certainly was a continuing, in its dynamics, a non-Indo-European language. Assumptively, these languages are considered by linguists as assorted and disconnected "dead" and not-so dead languages, such as proto-Turkic, Sumer, North-Caucasian, Dene-Caucasian, Basque, and many pre-IndoEuropean languages in Europe of 5000 - 2000 ybp, some later. The language of the Arbins may have been originally one language easily flowing through millennia and across Eurasia. However, this is a subject of another study.

\section{Acknowledgements}

The author is indebted to Susan Hedeen for her valuable help with the preparation of the manuscript.

\section{REFERENCES}

Balanovsky, O., Dibirova, K., Dybo, A., Mudrak, O., Frolova, S., Pocheshkhova, E. et al. (2012). Parallel evolution of genes and languages in the Caucasus region. Molecular Biology and Evolution, 29, 359-365

Balaresque, P., Bowden, G. R., Adams, S. M., Leung, H.-Y., King, T. E., Rosser, Z. H. et al. (2010). A predominantly Neolithic origin for European paternal lineages. PLoS Biology, 8, 1000285

Barac, L., Pericic, M., Klaric, I. M., Janicijevic, B., Parik, J., Rootsi, S. et al. (2003a). Y chromosome STRs in Croatians. Forensic Science International, 138, 127-133.

Barac, L., Pericic, M., Klaric, I. M., Rootsi, S., Janicijevic, B., Kivisild, T. et al. (2003b). Y chromosomal heritage of Croatian population and its island isolates. European Journal of Human Genetics, 11, 535542. doi:10.1038/sj.ejhg.5200992

Bengtson, J. D. (1997). The riddle of Sumerian: A Dene-Caucasian language? Mother Tongue, 3, 63-74.

Capelli, C., Brisighelli, F., Scarnicci, F., Arredi, B., Caglia, A., Vetrugno, G. et al. (2007). Y chromosome genetic variation in the Italian peninsula is clinal and supports an admixture model for the Meso- lithicNeolithic encounter. Molecular Phylogenetics and Evolution, 44, 228-239. doi:10.1016/j.ympev.2006.11.030

Cardoso, J. L. (2001). Le phenomene campaniformedans les basses 
vallees du Tage et du Sado (Portugal). In F. Nicolis (Ed.), Bell Beakers Today, Trento: Ufficio Beni Archeologici.

Cardoso, J. L., \& Soares, A. M. (1990). Chronologia absoluta para o campaniforme da Estremadura e do Sudoeste de Portugal. O Arqueologo Portugues, 8-10, 203-228.

Cinnioglu, C., King, R., Kivisild, T., Kalfoglu, E., Atasoy, S., Cavalleri, G. L. et al. (2004). Excavating Y-chromosome haplotype strata In Anatolia. Human Genetics, 114, 127-148. doi:10.1007/s00439-003-1031-4

Contu, D., Morelli, L., Santoni, F., Foster, J. W., Francalacci, P., Cucca, F. (2008). Y-Chromosome based evidence for pre-Neolithic origin of the genetically homogeneous but diverse Sardinian population: inference for association scans. PLOS ONE, 3. doi:10.1371/journal.pone

Cruciani, F., Trombetta, B., Sellitto, D., Massaia, A., Destro-Bisol, G., Watson, E. et al. (2010). Human Y chromosome haplogroup R-V88: A paternal genetic record of early mid Holocene trans-Saharan connections and the spread of Chadic languages. European Journal of Human Genetics, 18, 800-807. doi:10.1038/eihg.2009.231

Di Gaetano, C., Cerutti, N., Crobu, F., Robino, C., Inturri, S., Gino, S. et al. (2009). Differential Greek and northern African migrations to Sicily are supported by genetic evidence from the Y chromosome. European Journal of Human Genetics, 17, 91-99. doi:10.1038/ejhg.2008.120

Hammer, M. F., Behar, D. M., Karafet, T. M., Mendez, F. L., Hallmark, B., Erez, T. et al. (2009). Extended Y chromosome haplotypes resolve multiple and unique lineages of the Jewish priesthood. Human Genetics, 126, 707-717. doi:10.1007/s00439-009-0727-5

Herrera, K. J., Lowery, R. K., Hadden, L., Calderon, S., Chiou, C., Yepiskoposyan, L. et al. (2011). Neolithic patrineal signals indicate that the Armenian plateau was repopulated by agriculturalists. European Journal of Human Genetics, 20, 313-320.

doi:10.1038/ejhg.2011.192

Kang, L., Lu, Y., Wang, C., Hu, K., Chen, F., Liu, K. et al. (2011). Ychromosome O3 haplogroup diversity in Sino-Tibetan populations reveals two migration routes into the Eastern Himalayas. Annals of Human Genetics, 76, 92-99. doi:10.1111/j.1469-1809.2011.00690

Klyosov, A. A. (2008a). Mysteries of the "Western European" haplogroup R1b. Proceedings of the Russian Academy of DNA Genealogy, 1, 568-630 (in Russian).

Klyosov, A. A. (2008b). Origin of the Jews via DNA genealogy. Proceedings of the Russian Academy of DNA Genealogy, 1, 54-232.

Klyosov, A. A. (2009a). A comment on the paper: Extended Y chromosome haplotypes resolve multiple and unique lineages of the Jewish priesthood. Human Genetics, 126, 719-724. doi:10.1007/s00439-009-0739-1

Klyosov, A. A. (2009b). Once again on the "population mutation rate" of L. Zhivotovsky, or how fables are born. Proceedings of the Russian Academy of DNA Genealogy, 2, 1162-1181 (in Russian).

Klyosov, A. A. (2009c). DNA Genealogy, mutation rates, and some historical evidences written in Y-chromosome. I. Basic principles and the method. Journal of Genetic Genealogy, 5, 186-216.

Klyosov, A. A. (2009d). DNA Genealogy, mutation rates, and some historical evidences written in Y-chromosome. II. Walking the map. Journal of Genetic Genealogy, 5, 217-256.

Klyosov, A. A. (2010a). Haplogroup R1b1 and its subclades in Asia. Proceedings of the Russian Academy of DNA Genealogy, 3, 16761695 (in Russian).

Klyosov, A. A. (2010b). Haplotypes of haplogroup R1b in central Africa. Proceedings of the Russian Academy of DNA Genealogy, 3, 369-378 (in Russian)

Klyosov, A. A. (2010c). Haplogroup R1b. Part 2. Proceedings of the Russian Academy of DNA Genealogy, 3, 406-475 (in Russian).

Klyosov, A. A. (2010d). The "age" of subclade R1b1a2-M269 and its subclades (L23, L51, L11). Proceedings of the Russian Academy of DNA Genealogy, 3, 1310-1315 (in Russian).

Klyosov, A. A. (2010e). Irish haplotypes and haplogroups. Proceedings of the Russian Academy of DNA Genealogy, 3, 1029-1053.

Klyosov, A. A. (2011a). Origin of ancient subclades of haplogroup $\mathrm{R} 1 \mathrm{~b}$ - Regions and times. Proceedings of the Russian Academy of
DNA Genealogy, 4, 2227-2245 (in Russian).

Klyosov, A. A. (2011b). Haplotypes of R1b1a2-P312 and related subclades: Origin and "ages" of most recent common ancestors. Proceedings of the Russian Academy of DNA Genealogy, 4, 1127-1195.

Klyosov, A. A. (2011c). Haplogroups and haplotypes in Armenia (haplogroups J2, R1b-L23, R1b-M269, and T-M184). Proceedings of the Russian Academy of DNA Genealogy, 4, 1985-1993 (in Russian).

Klyosov, A. A. (2011d). "Out of Africa" theory re-examined. Proceedings of the Russian Academy of DNA Genealogy, 4, 1908-1977 (in Russian).

Klyosov, A. A., \& Rozhanskii, I. L. (2012a). Haplogroup R1a as the Proto-Endo-Europeans and the legendary Aryans as witnessed by the DNA of their current descendants. Advances in Anthropology, 2, 113. doi:10.4236/aa.2012.21001

Klyosov, A. A., \& Rozhanskii, I. L. (2012b). Re-examining the "out of africa" theory and the origin of Europeoids (Caucasoids) in light of DNA genealogy. Advances in Anthropology, 2, in press.

Kramer, S. N. (1971). The Sumerians: Their history, culture, and character. Chicago, IL: University of Chicago Press.

Lashgary, Z., Khodadadi, A., Singh, Y., Houshmand, S. M., Mahjoubi, F., Sharma, P. et al. (2011). Y chromosome diversity among the Iranian religious groups: A reservoir of genetic variations. Annals of Human Biology, 38, 364-372.

Lobov, A. S. (2009). Structure of the gene pool of the Bashkir subpopulations. Ufa. http://ftp.anrb.ru/molgen/Lobov AS.PDF

Mallory, J. P. (1989). In search of the indo-Europeans: Language, archaeology and myth. London: Thames and Hudson.

Malyarchuk, B., Derenko, M., Denisova, G., Maksimov, A., Wozniak, M., Grzybowski, T. et al. (2011). Ancient links between Siberians and native Americans revealed by subtyping the $\mathrm{Y}$ chromosome haplogroup Q1a. Journal of Human Genetics, 56, 583-588.

Martinez, P. V., Lull, V., \& Mico, R. (1996). El vaso campaniforme, in: Cronologia de la Prehistoria Reciente de la Peninsula Iberica y Baleares (c. 2800-900 cal. A.N.E.). British Archaeological Reports, International Series 652, 105-110.

Morelli, L., Contu, D., Santoni, F., Whalen, M., Francalacci, P., \& Cucca, F. (2010). A comparison of Y-chromosome variation in Sardinia and Anatolia is more consistent with cultural rather than demic diffusion of agriculture. PLOS ONE, 5, e10419. doi:10.1371/journal.pone.0010419

Muller, J., \& Van Willigen, S. (2001). New radiocarbon evidence for European Bell Beakers and the consequences for the diffusion of the Bell Beaker phenomenon. In F. Nicolis (Ed.), Bell Beakers Today, Trento: Ufficio Beni Archeologici.

Myres, N. M., Rootsi, S., Lin, A. A., Jarve, M., King, R. J., Kutuev, I. et al. (2010). A major Y-chromosome haplogroup R1b holocene era founder effect in central and western Europe. European Journal of Human Genetics, 19, 95-101.

Nocete, F. (2006). The first specialized copper industry in the Iberian Peninsula: Cabezo Jure (2900-2200 BC). Antiquity, 80, 646-657.

Pericic, M., Lauc, L. B., Klaric, A. M. et al. (2005). High-resolution phylogenetic analysis of southeastern Europe traces major episodes of paternal gene flow among Slavic populations. Molecular Biology and Evolution, 22, 1964-1975. doi:10.1093/molbev/msi185

Roewer L., Willuweit S., Kruger C., Nagy M., Rychkov S., Morozowa I. et al. (2008). Analysis of Y chromosome STR haplotypes in the European part of Russia reveals high diversities but non-significant genetic distances between populations. International Journal of Legal Medicine, 122, 219-223. doi:10.1007/s00414-007-0222-2

Rozhanskii, I. L., \& Klyosov, A. A. (2011). Mutation rate constants in DNA genealogy (Y chromosome). Advances in Anthropology, 1, 2634. doi:10.4236/aa.2011.12005

Semino, O., Passarino, G., Oefner, P. J., Lin, A. A., Arbuzova, S., Beckman, L. E. et al. (2000). The genetic legacy of paleolithic Homo sapiens sapiens in extant Europeans: A Y chromosome perspective. Science, 290, 1155-1159. doi:10.1126/science.290.5494.1155

Underhill, P. A., Myres, N. M., Rootsi, S., Metspalu, M., Zhivotovsky, M. A., King, R. J. et al. (2009). Separating the post-Glacial coances- 


\section{A. A. KLYOSOV}

try of European and Asian Y chromosomes within haplogroup R1a. European Journal of Human Genetics, 18, 479-484.

Weale, M. E., Yepiskoposyan, L., Jager, R. F., Hovhannisyan, N., Khudoyan, A., Barbage-Hall, O. et al. (2001). Armenian Y chromosome haplotypes reveal strong regional structure within a single ethnonational group. Human Genetics, 109, 659-674. doi:10.1007/s00439-001-0627-9

Wells, R. S., Yuldasheva, N., Ruzibakiev, R., Underhill, P. A., Evseeva, I., Blue-Smith, J. et al (2001). The Eurasian heartland: a continental perspective on Y-chromosome diversity. Proceedings of the National Academy of Sciences USA, 98, 10244-10249. doi:10.1073/pnas.171305098

Wiik, K. (2008). Where did European men come from? Journal of Genetic Genealogy, 4, 35-85.

Zakharov, S. V. (2010). On the origin of Botai culture. Vestnik of Ar-

\section{APPENDIX}

The following DNA projects were selected as primary haplotype databases:

http://www.familytreedna.com/public/R1b1b1/default.aspx?s ection=yresults

http://www.familytreedna.com/public/ht35new/default.aspx

http://www.familytreedna.com/public/AssyrianHeritageDNA

Project/default.aspx?section=yresults chaeology, Anthropology, and Ethnography, 1, 49-58.

Zalloua, P. A., Xue, Y., Khalife, J., Makhoul, N., Debiane, L., Platt, D. E. et al. (2008). Y-Chromosomal diversity in Lebanon is structured by recent historical events. American Journal of Human Genetics, 82, 973-882. doi:10.1016/j.ajhg.2008.01.020

Zhivotovsky, L. A., Underhill, P. A., Cinnioglu, C., Kayser, M., Morar, B., Kivisild, T. et al. (2004). The effective mutation rate at Y-chromosome short tandem repeats, with application to human population divergence time. American Journal of Human Genetics, 74, 50-61. doi:10.1086/380911

Zhong, H., Shi, H., Qi, X.-B., Duan, Z.-Y., Tan, P.-P., Jin, L. et al. (2010). Extended Y-chromosome investigation suggests post-Glacial migrations of modern humans into East Asia via the northern route Molecular Biology and Evolution, 28, 717-727.

http://www.familytreedna.com/public/IrelandHeritage/defaul t.aspx?section=yresults

http://www.familytreedna.com/public/R-L21/default.aspx?se ction=yresults

Reference data were selected according to SNP assignment from YSearch database: (http://www.ysearch.org) and public projects of FTDNA (http://www.familytreedna.com) 